\title{
Zinc complexes of diflunisal: synthesis, characterization, structure, antioxidant activity, and in vitro and in silico study of the interaction with DNA and albumins
}

\section{Alketa Tarushi, ${ }^{\text {a }}$ Chrisoula Kakoulidou, ${ }^{\text {a }}$ Catherine P. Raptopoulou, ${ }^{\text {b }}$ Vassilis Psycharis, ${ }^{\text {b }}$

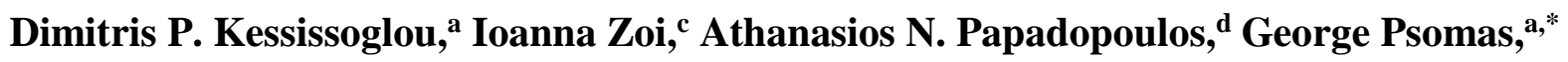

${ }^{a}$ Department of General and Inorganic Chemistry, Faculty of Chemistry, Aristotle University of Thessaloniki, P.O. Box 135, GR-54124 Thessaloniki, GREECE.

${ }^{b}$ Institute of Nanoscience and Nanotechnology, NCSR “Demokritos”, GR-15310 Aghia Paraskevi Attikis, GREECE.

${ }^{c}$ Department of Chemistry and Biochemistry, University of Arizona, USA

${ }^{d}$ Department of Nutrition and Dietetics, Faculty of Food Technology and Nutrition, Alexandrion Technological Educational Institution, Sindos, Thessaloniki, GREECE.

\begin{abstract}
From the reaction of $\mathrm{ZnCl}_{2}$ with the non-steroidal anti-inflammatory drug diflunisal (Hdifl), complex [Zn(difl-O) $\left.)_{2}(\mathrm{MeOH})_{4}\right], \mathbf{1}$ was formed, while in the presence of a N,N'-donor heterocyclic ligand 2,2'-bipyridylamine (bipyam), 2,2'-bipyridine (bipy), 1,10-phenanthroline (phen) and 2,2'dipyridylketone oxime (Hpko), the complexes [Zn(difl-O,O') $)_{2}($ bipyam)], 2, [Zn(difl-O,O')2(bipy)], 3, [Zn(difl-O,O' $)_{2}$ (phen)], 4 and [Zn(difl-O) $\left.)_{2}(\text { Hpko })_{2}\right], 5$ were isolated, respectively. The complexes were characterized by physicochemical and spectroscopic techniques and the crystal structures of complexes 2, 3 and 5 were determined by X-ray crystallography. The ability of the complexes to scavenge 1,1-diphenyl-picrylhydrazyl, 2,2'-azinobis(3-ethylbenzothiazoline-6-sulfonic acid) and hydroxyl radicals and to inhibit soybean lipoxygenase was studied and the complexes were more active than free Hdifl. The interaction of the complexes with serum albumins was monitored by fluorescence emission spectroscopy and the corresponding binding constants were calculated. UV-
\end{abstract}

\footnotetext{
${ }^{*}$ Corresponding author:

Tel.:+30+2310997790; Fax:+30+2310997738; E-mail: gepsomas@chem.auth.gr
} 
vis spectroscopy, viscosity measurements and fluorescence emission spectroscopy for the competitive studies of the complexes with ethidium bromide were employed to investigate the interaction of the complexes with calf-thymus DNA and revealed intercalation as the most possible DNA-binding mode. Computational techniques were used to identify possible binding sites both albumins and DNA, and determine the druggability of human and bovine serum albumins with the five novel complexes. The majority of the complexes are stronger binders than the free Hdifl. This is the first study incorporating experimental and computational results to explore the binding activity of metal-NSAID complexes with DNA and serum albumins, suggesting their application as potential metallodrugs.

Keywords: Diflunisal; zinc complexes; biological activity; Interaction with DNA; Interaction with albumins; molecular docking.

\section{Introduction}

Non-steroidal anti-inflammatory drugs (NSAIDs) are among the most frequently used analgesic, anti-inflammatory and antipyretic agent despite their gastrointestinal and renal sideeffects [1]. The main mode of action of the NSAIDs is the inhibition of the cyclooxygenasemediated production of prostaglandins [2]. Furthermore, NSAIDs have shown synergism on the activity of certain antitumor drugs [3] and have presented antitumor activity leading to cell death of cancer cell lines via apoptosis [4] or mechanisms with the involvement of free radicals [5,6]. The study of interaction with DNA and the evaluation of antioxidant activity of NSAIDs and their compounds are of great importance as an initial approach of their potential anti-inflammatory and anticancer activity [7].

According to the existing characteristic chemical groups, the chemical classes of NSAIDs include phenylalkanoate, anthranilate and salicylate derivatives bearing a carboxylic group as well as oxicams, sulfonamides and furanones [8]. Diflunisal (Hdifl, Fig. 1(A)) is a difluoro-derivative of salicylic acid showing analgesic and anti-inflammatory activity and was produced in 1971 as a potent chemical analog of aspirin [9]. The duration of action of Hdifl is twelve hours or more and Hdifl is mainly used in the chronic treatment of symptoms of arthritis [10] and for the relief of acute pain following oral surgery, such as removal of wisdom teeth [11]. According to the literature, only the crystal structures of $\mathrm{Cu}(\mathrm{II})$ [12], $\mathrm{Co}(\mathrm{II})$ [13] and $\mathrm{Ni}(\mathrm{II})$ [14] complexes with diflunisal as ligands have been reported, all by our group. 
Zinc is the second most abundant transition metal in the human body. Zinc is involved in the regulation of cell metabolism $[15,16]$ and has catalytic, structural or regulatory role in more than two hundred metalloenzymes [17]. Zinc is the only metal ion able to facilitate the rewinding of DNA [18]. Zinc compounds are the active ingredients of medicaments used for the treatment of skin injuries. Furthermore, the extensive use of zinc in the form of "Baby Zinc" has saved the lives of many children suffering from deadly diarrhea in Asian and African countries [19]. Additionally, many zinc complexes have shown anticonvulsant [20], antidiabetic [21], anti-inflammatory [22], antimicrobial [23-26], antioxidant [27,28] and anticancer [29,30] activity and some others have been tested for the treatment of Alzheimer disease [31]. Concerning the structurally characterized zinc complexes with NSAIDs [32], their number is still expanding including Zn(II) complexes with aspirine [33], diclofenac [34], flufenamic acid [35,36] ibuprofen [37], indomethacin [23], mefenamic acid [27] and tolfenamic acid [28,38] as ligands.

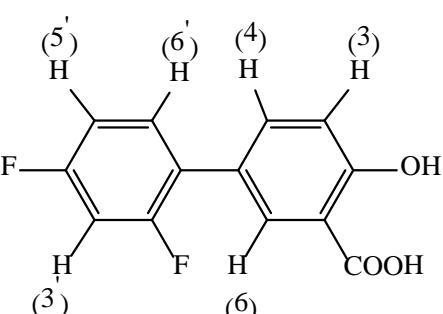

(A)

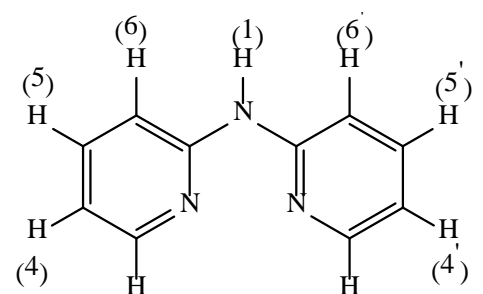

(3)

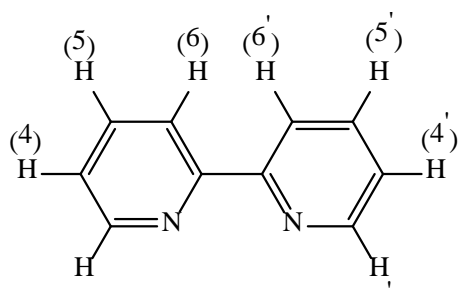

(3)
(3)

(C)

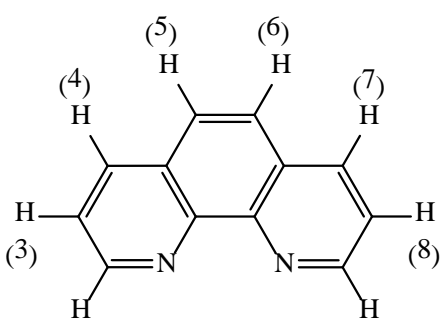

(2)
(9)

(D)

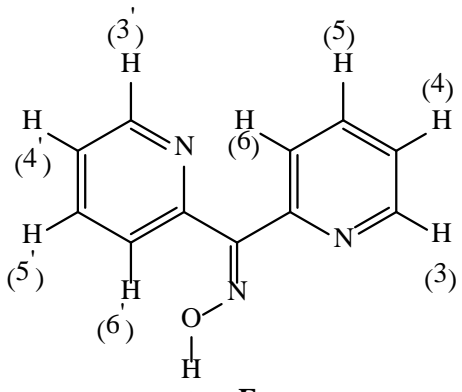

(1) (E)

Fig. 1. The syntax formula and hydrogen numbering of (A) diflunisal (Hdifl), (B) 2,2'bipyridylamine (bipyam), (C) 2,2'-bipyridine (bipy), (D) 1,10-phenanthroline (phen) and (E) 2,2'dipyridylketone oxime (Hpko).

As a continuation of our recent studies concerning metal-NSAID complexes [12-14,2628,32,35,36,38-46], we have synthesized and characterized the Zn(II) complexes with diflunisal in the absence or presence of the nitrogen-donors 2,2'-bipyridylamine (bipyam), 2,2'-bipyridine (bipy), 1,10-phenanthroline (phen) or 2,2'-dipyridylketone oxime (Hpko) as co-ligands (Figure 1(B)-(E)). The resultant complexes [Zn(difl-O) $\left.)_{2}(\mathrm{MeOH})_{4}\right], \mathbf{1}$, [Zn(difl-O)(difl-O,O')(bipyam)] $\mathrm{MeOH}$, 2·MeOH, [Zn(difl-O,O') $)_{2}$ (bipy)], 3, [Zn(difl-O,O') ${ }_{2}$ (phen)], 4 and [Zn(difl-O) $)_{2}$ (Hpko- 
$\left.\left.\mathrm{N}, \mathrm{N}^{\prime}\right)_{2}\right] \cdot 0.2 \mathrm{H}_{2} \mathrm{O}, 5 \cdot 0.2 \mathrm{H}_{2} \mathrm{O}$ were characterized by physicochemical (elemental analysis and molecular conductivity) and spectroscopic (IR, UV-vis and ${ }^{1} \mathrm{H}-\mathrm{NMR}$ ) techniques. Additionally, the crystal structures of [Zn(difl-O)(difl-O,O')(bipyam)]· $\mathrm{MeOH}, 2 \cdot \mathrm{MeOH},[\mathrm{Zn}($ difl-O,O')2(bipy)], 3 and [Zn(difl-O) $)_{2}(\text { Hpko-N,N') })_{2} \mathbf{5}$ were determined by X-ray crystallography. The potential biological activity of the complexes was investigated in vitro, regarding: (i) their ability to scavenge 1,1diphenyl-picrylhydrazyl (DPPH), hydroxyl radicals (•OH) and 2,2'-azinobis-(3ethylbenzothiazoline-6-sulfonic acid) $\left(\mathrm{ABTS}^{+\bullet}\right.$ ) radicals and to inhibit soybean lipoxygenase (LOX) activity, (ii) their binding affinity towards bovine (BSA) and human serum albumin (HSA) by fluorescence spectroscopy, (iii) their binding mode and affinity to calf-thymus (CT) DNA examined by UV spectroscopy and viscosity measurements and via their ability to displace ethidium bromide (EB) from the EB-DNA compound investigated by fluorescence emission spectroscopy, as well as in silico, utilizing molecular docking simulations to study possible interactions between the complexes 1-5 and the proteins mentioned above.

\section{Experimental}

\subsection{Materials - Instrumentation - Physical measurements}

Diflunisal, bipy, bipyam, phen, $\mathrm{Hpko}, \mathrm{ZnCl}_{2}, \mathrm{KOH}$, trisodium citrate, $\mathrm{NaCl}, \mathrm{CT}$ DNA, BSA, HSA, EB, DPPH, ABTS, sodium linoleate, butylated hydroxytoluene (BHT), 6-hydroxy-2,5,7,8tetramethylchromane-2-carboxylic acid (trolox), nordihydroguaiaretic (NDGA) and caffeic acid were purchased from Sigma-Aldrich and all solvents were purchased from Merck. All the chemicals and solvents were reagent grade and were used as purchased.

DNA stock solution was prepared by dilution of CT DNA to buffer (containing $150 \mathrm{mM}$ $\mathrm{NaCl}$ and $15 \mathrm{mM}$ trisodium citrate at $\mathrm{pH}$ 7.0) followed by exhaustive stirring at $4^{\circ} \mathrm{C}$ for three days, and kept at $4^{\circ} \mathrm{C}$ for no longer than two weeks. The stock solution of CT DNA gave a ratio of UV absorbance at 260 and $280 \mathrm{~nm}\left(\mathrm{~A}_{260} / \mathrm{A}_{280}\right)$ in the range 1.85-1.90, indicating that the DNA was sufficiently free of protein contamination [47]. The concentration of CT DNA was determined by the UV absorbance at $260 \mathrm{~nm}$ after 1:20 dilution using $\varepsilon=6600 \mathrm{M}^{-1} \mathrm{~cm}^{-1}$ [48].

Infrared (IR) spectra (400-4000 $\mathrm{cm}^{-1}$ ) were recorded on a Nicolet FT-IR 6700 spectrometer with samples prepared as $\mathrm{KBr}$ pellets. UV-visible (UV-vis) spectra were recorded as nujol mulls and in solution at concentrations in the range $10^{-5}-10^{-3} \mathrm{M}$ on a Hitachi U-2001 dual beam spectrophotometer. ${ }^{1} \mathrm{H}-\mathrm{NMR}$ spectra were measured at room temperature on a Bruker AM300 NMR spectrometer using DMSO- $\mathrm{d}_{6}$ as solvent. $\mathrm{C}, \mathrm{H}$ and $\mathrm{N}$ elemental analysis were performed on a Perkin-Elmer 240B elemental analyzer. Molar conductivity measurements were carried out in 1mM 
DMSO solution of the complexes with a Crison Basic 30 conductometer. Fluorescence spectra were recorded in solution on a Hitachi F-7000 fluorescence spectrophotometer. Viscosity experiments were carried out using an ALPHA L Fungilab rotational viscometer equipped with an $18 \mathrm{~mL}$ LCP spindle.

\subsection{Synthesis of the compounds}

\subsubsection{Synthesis of $\left[\mathrm{Zn}(\operatorname{difl})_{2}(\mathrm{MeOH})_{4}\right], 1$}

A methanolic solution (15 mL) containing diflunisal $(0.4 \mathrm{mmol}, 100 \mathrm{mg})$ and $\mathrm{KOH}(0.4$ mmol, $23 \mathrm{mg}$ ) was added dropwise and after stirring for $1 \mathrm{~h}$, to a methanolic solution (10 mL) of $\mathrm{ZnCl}_{2}(0.2 \mathrm{mmol}, 28 \mathrm{mg})$ and the reaction mixture was stirred for $1 \mathrm{~h}$. The reaction solution was filtered and left to slowly evaporate. After a few days colorless microcrystalline product of [Zn(difl $\left.)_{2}(\mathrm{MeOH})_{4}\right], 1$ (90 mg, 65\%) was deposited and collected by filtration. Anal. calcd. for $\mathrm{C}_{30} \mathrm{H}_{30} \mathrm{~F}_{4} \mathrm{O}_{10} \mathrm{Zn}(\mathrm{MW}=691.94)$ : C, 52.08; H, 4.37\%; found: C, 51.87; H, 4.25\%. IR (KBr disk), $v_{\max } / \mathrm{cm}^{-1}: v_{\text {asym }}\left(\mathrm{CO}_{2}\right): 1591$ (vs (very strong)); $v_{\text {sym }}\left(\mathrm{CO}_{2}\right): 1381$ (strong (s)); $\Delta v\left(\mathrm{CO}_{2}\right)=v_{\text {asym }}\left(\mathrm{CO}_{2}\right)$

- $v_{\text {symm }}\left(\mathrm{CO}_{2}\right)=210 \mathrm{~cm}^{-1}$. UV-vis: as nujol mull, $\lambda / \mathrm{nm}$ : 312 (sh (shoulder)), 293; in DMSO, $\lambda / \mathrm{nm}$ ( $\left(\mathrm{M}^{-1} \mathrm{~cm}^{-1}\right)$ : 310 (sh) (8500), 291 (sh) (15300). ${ }^{1} \mathrm{H}-\mathrm{NMR}$ in DMSO-d 6 , $\delta / \mathrm{ppm}$ : 6.87 (2H, d, $\mathrm{H}^{3}$-difl),

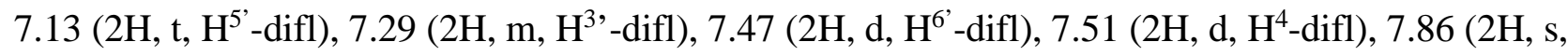
$\mathrm{H}^{6}$-difl). The complex is soluble in DMF and DMSO $\left(\Lambda_{\mathrm{M}}=7 \mathrm{~S} \cdot \mathrm{cm}^{2} \cdot \mathrm{mol}^{-1}, 1 \mathrm{mM}\right.$ in DMSO).

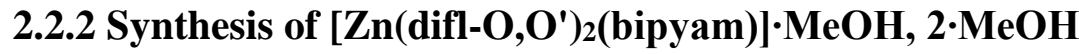

A methanolic solution (8 mL) of Hdifl (0.4 mmol, $100 \mathrm{mg})$ and $\mathrm{KOH}(0.4 \mathrm{mmol}, 22 \mathrm{mg})$ after $1 \mathrm{~h}$ stirring was added dropwise slowly and simultaneously with a methanolic solution $(8 \mathrm{~mL})$ of bipyam $(0.2 \mathrm{mmol}, 34 \mathrm{mg})$ to a methanolic solution $(8 \mathrm{~mL})$ of $\mathrm{ZnCl}_{2}(0.2 \mathrm{mmol}, 27 \mathrm{mg})$. The resultant solution was stirred for $30 \mathrm{~min}$ and was left for slow evaporation. Colorless crystals of [Zn(difl) 2 (bipyam)] $\mathrm{MeOH}, 2 \cdot \mathrm{MeOH}(85 \mathrm{mg}, 55 \%)$ suitable for X-ray structure determination, were collected after two weeks. Anal. calcd. for $\left[\mathrm{Zn}(\text { difl })_{2}(\right.$ bipyam) $] \cdot \mathrm{MeOH}, \mathrm{C}_{37} \mathrm{H}_{27} \mathrm{~F}_{4} \mathrm{~N}_{3} \mathrm{O}_{7} \mathrm{Zn}(\mathrm{MW}=$ 766.99): C, 57.94; H, 3.55; N, 5.48\%; found: C, 57.75; H, 3.45; N, 5.65\%. IR (KBr disk): $v_{\max } / \mathrm{cm}^{-}$ 1: $v_{\text {asym }}\left(\mathrm{CO}_{2}\right): 1587(\mathrm{~s}) ; v_{\text {sym }}\left(\mathrm{CO}_{2}\right): 1395(\mathrm{~s}) ; \Delta v\left(\mathrm{CO}_{2}\right)=192 \mathrm{~cm}^{-1} ; \rho(\mathrm{C}-\mathrm{H})_{\text {bipyam: }}$ 763(m (medium)). UV-vis: as nujol mull, $\lambda / \mathrm{nm}$ : 319, 273; in DMSO, $\lambda / \mathrm{nm}\left(\varepsilon / \mathrm{M}^{-1} \mathrm{~cm}^{-1}\right)$ : 316 (5000), 269 (9700). ${ }^{1} \mathrm{H}-$

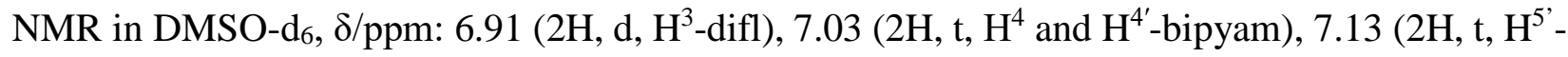
difl), 7.28 (2H, m, $\mathrm{H}^{3}$-difl), 7.50 (6H, m, $\mathrm{H}^{6^{\prime}}$-difl, $\mathrm{H}^{4}$-difl, $\mathrm{H}^{6}$-bipyam and $\mathrm{H}^{6^{\prime}}$-bipyam), 7.81 (2H, t, 
$\mathrm{H}^{5}$ and $\mathrm{H}^{5^{\prime}}$-bipyam), 7.95 (2H, s, $\mathrm{H}^{6}$-difl), 8.34 (2H, d, $\mathrm{H}^{3}$ and $\mathrm{H}^{3^{\prime}}$-bipyam), $10.16\left(1 \mathrm{H}, \mathrm{s}, \mathrm{H}^{1}\right.$ bipyam). The complex is soluble in DMSO $\left(\Lambda_{\mathrm{M}}=8 \mathrm{~S} \cdot \mathrm{cm}^{2} \cdot \mathrm{mol}^{-1}, 1 \mathrm{mM}\right.$ in DMSO).

\subsubsection{Synthesis of complexes 3-5}

Complexes 3-5 were prepared in a similar way to 2 with the use of bipy $(0.2 \mathrm{mmol}, 31 \mathrm{mg})$ for 3, phen (0.2 mmol, $36 \mathrm{mg}$ ) for 4 and Hpko (0.4 mmol, $80 \mathrm{mg})$ for 5, instead of bipyam.

[Zn(difl-O,O')2(bipy)], 3: Colorless crystals of [Zn(difl)2(bipy)], 3 (85 mg, 60\%) suitable for X-ray structure determination, were collected after three weeks. Anal. calcd. for $\mathrm{C}_{36} \mathrm{H}_{22} \mathrm{~F}_{4} \mathrm{~N}_{2} \mathrm{O}_{6} \mathrm{Zn}$ (MW = 719.92): C, 60.06; H, 3.08; N, 3.89\%; found: C, 60.15; H, 3.15; N, 4.04\%. IR (KBr disk): $v_{\max } / \mathrm{cm}^{-1}: v_{\text {asym }}\left(\mathrm{CO}_{2}\right): 1591$ (s); $v_{\text {sym }}\left(\mathrm{CO}_{2}\right): 1397$ (s); $\Delta v\left(\mathrm{CO}_{2}\right)=194 \mathrm{~cm}^{-1} ; \rho(\mathrm{C}-\mathrm{H})_{\text {bipy: }}$ 764(m). UVvis: as nujol mull, $\lambda / \mathrm{nm}$ : 316, 282; in DMSO, $\lambda / \mathrm{nm}\left(\varepsilon / \mathrm{M}^{-1} \mathrm{~cm}^{-1}\right)$ : 312 (sh) (4200), 279 (14800). ${ }^{1} \mathrm{H}-$

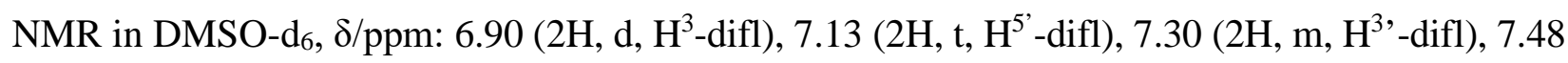
(2H, d, $\mathrm{H}^{6}$-difl and $\mathrm{H}^{4}$-difl), 7.65 (2H, t, $\mathrm{H}^{4}$ and $\mathrm{H}^{4^{\prime}}$-bipy), 7.89 (2H, s, $\mathrm{H}^{6}$-difl), 8.15 (2H, t, $\mathrm{H}^{5}$ and $\mathrm{H}^{5^{\prime}}$-bipy), 8.53 (2H, d, $\mathrm{H}^{6}$ and $\mathrm{H}^{6^{\prime}}$-bipy), 8.74 (2H, d, $\mathrm{H}^{3}$ and $\mathrm{H}^{3^{\prime}}$-bipy). The complex is soluble in $\operatorname{DMSO}\left(\Lambda_{\mathrm{M}}=6 \mathrm{~S} \cdot \mathrm{cm}^{2} \cdot \mathrm{mol}^{-1}, 1 \mathrm{mM}\right.$ in DMSO$)$.

[Zn(difl-O,O')2(phen)], 4: Microcrystalline colorless product of [Zn(difl)2(phen)], 4 (95 mg, $65 \%$ ) was collected with filtration after two weeks. Anal. calcd. for $\mathrm{C}_{38} \mathrm{H}_{22} \mathrm{~F}_{4} \mathrm{~N}_{2} \mathrm{O}_{6} \mathrm{Zn}(\mathrm{MW}=$ 743.98): C, 61.35; H, 2.98; N, 3.77\%; found: C, 61.25; H, 2.94; N, 3.83\%. IR (KBr disk), $v_{\max } / \mathrm{cm}^{-}$ 1; $v_{\text {asym }}\left(\mathrm{CO}_{2}\right): 1590(\mathrm{~s}) ; v_{\text {sym }}\left(\mathrm{CO}_{2}\right): 1395$ (vs); $\Delta v\left(\mathrm{CO}_{2}\right)=195 \mathrm{~cm}^{-1} ; \rho(\mathrm{C}-\mathrm{H})_{\text {phen: }}: 726(\mathrm{~m})$. UV-vis: as nujol mull, $\lambda / \mathrm{nm}$ : 320(sh), 280; in DMSO, $\lambda / \mathrm{nm}\left(\varepsilon / \mathrm{M}^{-1} \mathrm{~cm}^{-1}\right)$ : 318 (sh) (2750), 277 (13200). ${ }^{1} \mathrm{H}-$

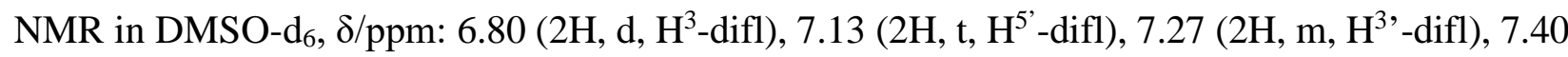
(2H, m, H $6^{6}$-difl), 7.48 (2H, m, H4-difl), 7.87 (2H, s, $\mathrm{H}^{6}$-difl), 8.11 (2H, d, $\mathrm{H}^{3}$ - and $\mathrm{H}^{8}$-phen), 8.28 (2H, d, $\mathrm{H}^{5}$ - and $\mathrm{H}^{6}$-phen), $8.90\left(4 \mathrm{H}, \mathrm{m}, \mathrm{H}^{2}-, \mathrm{H}^{4}\right.$-, $\mathrm{H}^{7}$ - and $\mathrm{H}^{9}$-phen). The complex is soluble in DMF and DMSO $\left(\Lambda_{\mathrm{M}}=10 \mathrm{~S} \cdot \mathrm{cm}^{2} \cdot \mathrm{mol}^{-1}, 1 \mathrm{mM}\right.$ in DMSO $)$.

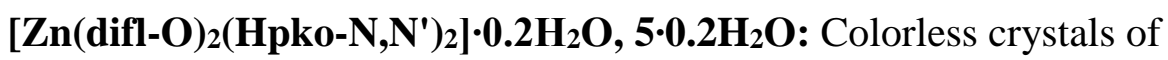
[Zn(difl $\left.)_{2}(\mathrm{Hpko})_{2}\right] \cdot 0.2 \mathrm{H}_{2} \mathrm{O}, 5 \cdot 0.2 \mathrm{H}_{2} \mathrm{O}(115 \mathrm{mg}, 60 \%)$ suitable for X-ray structure determination, were collected after twenty days. Anal. calcd. for [ $\left.\mathrm{Zn}(\text { difl })_{2}(\mathrm{Hpko})_{2}\right], \mathrm{C}_{48} \mathrm{H}_{32} \mathrm{~F}_{4} \mathrm{~N}_{6} \mathrm{O}_{8} \mathrm{Zn}(\mathrm{MW}=$ 962.19): C, 59.92; H, 3.35; N, 8.73\%; found: C, 59.58; H, 3.37; N, 8.53\%. IR (KBr disk), $v_{\max } / \mathrm{cm}^{-}$ 1; vasym $\left(\mathrm{CO}_{2}\right): 1598$ (vs); v vym $\left(\mathrm{CO}_{2}\right): 1374$ (s); $\Delta v\left(\mathrm{CO}_{2}\right)=224 \mathrm{~cm}^{-1} ; \rho(\mathrm{C}-\mathrm{H})_{\mathrm{Hpko}}: 785$ (m). UV-vis: as nujol mull, $\lambda / \mathrm{nm}$ : 326, 279; in DMSO, $\lambda / \mathrm{nm}\left(\varepsilon / \mathrm{M}^{-1} \mathrm{~cm}^{-1}\right)$ : 328 (6900), 273 (15700). ${ }^{1} \mathrm{H}-\mathrm{NMR}$ in

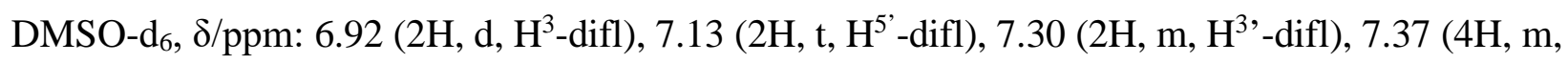
$\mathrm{H}^{4}$ and $\mathrm{H}^{4^{\prime}}$-Hpko), 7.50 (4H, m, $\mathrm{H}^{6^{\prime}}$-difl, $\mathrm{H}^{4}$-difl and $\mathrm{H}^{6^{\prime}}$-Hpko), 7.81 (2H, m, $\mathrm{H}^{6}$-Hpko), 7.86 (4H, 
m, $\mathrm{H}^{5}$ and $\mathrm{H}^{5^{\prime}}$-Hpko), 7.98 (2H, s, $\mathrm{H}^{6}$-difl), 8.42 (2H, d, $\mathrm{H}^{3^{\prime}}$-Hpko), 8.57 (2H, d, $\mathrm{H}^{3}$-Hpko), 11.86 (2H, s, $\mathrm{H}^{1}$-Hpko). The complex is soluble in DMF and DMSO $\left(\Lambda_{\mathrm{M}}=10 \mathrm{~s} \cdot \mathrm{cm}^{2} \cdot \mathrm{mol}^{-1}, 1 \mathrm{mM}\right.$ in DMSO).

\subsection{X-ray Crystal Structure Determination}

Crystals of $2 \cdot \mathrm{MeOH}(0.09 \times 0.36 \times 0.43 \mathrm{~mm}), 3(0.08 \times 0.26 \times 0.61 \mathrm{~mm})$ and $\mathbf{5} \cdot 0.2 \mathrm{H}_{2} \mathrm{O}$ $(0.26 \times 0.37 \times 0.49 \mathrm{~mm})$ were taken from the mother liquor and immediately cooled to $-93{ }^{\circ} \mathrm{C}$ (2· $\mathrm{MeOH}, 3)$ or $-113^{\circ} \mathrm{C}(5)$. Diffraction measurements were made on a Rigaku R-AXIS SPIDER Image Plate diffractometer using graphite monochromated $\mathrm{Cu} \mathrm{K} \alpha$ radiation. Data collection ( $\omega$ scans) and processing (cell refinement, data reduction and Empirical absorption correction) were performed using the CrystalClear program package [49]. Important crystallographic data are listed in Table S1. The structures were solved by direct methods using SHELXS-97 and refined by fullmatrix least-squares techniques on $\mathrm{F}^{2}$ with SHELXL-97 [50]. Further experimental crystallographic details for 2'MeOH: $2 \theta_{\max }=134^{\circ}$; reflections collected/unique/used, 22621/5511 [ $\left.\mathrm{R}_{\text {int }}=0.0262\right] /$ 5511; 566 parameters refined; $(\Delta / \sigma)_{\max }=0.005 ;(\Delta \rho)_{\max } /(\Delta \rho)_{\min }=0.387 /-0.473 \mathrm{e} / \AA^{3} ; R 1 / \mathrm{w} R 2$ (for all data), $0.0430 / 0.0898$. Further experimental crystallographic details for 3 : $2 \theta_{\max }=134^{\circ}$; reflections collected/unique/used, 30169/5290 [ $\left.\mathrm{R}_{\text {int }}=0.0505\right] / 5290 ; 526$ parameters refined; $(\Delta / \sigma)_{\max }=0.001$; $(\Delta \rho)_{\max } /(\Delta \rho)_{\min }=1.266 /-0.440 \mathrm{e} / \AA^{3} ; R 1 / \mathrm{w} R 2$ (for all data), 0.0497/0.1296. Further experimental crystallographic details for $\mathbf{5} \cdot 0.2 \mathrm{H}_{2} \mathrm{O}: 2 \theta_{\max }=134^{\circ}$; reflections collected/unique/used, 24688/7139 $\left[\mathrm{R}_{\text {int }}=0.0264\right] / 7139 ; 738$ parameters refined; $(\Delta / \sigma)_{\max }=0.005 ;(\Delta \rho)_{\max } /(\Delta \rho)_{\min }=0.626 /-0.360 \mathrm{e} / \AA^{3}$; $R 1 / w R 2$ (for all data), 0.0379/0.0959. All hydrogen atoms were located by difference maps and were refined isotropically or were introduced at calculated positions as riding on bonded atoms. All non-hydrogen atoms were refined anisotropically.

\subsection{Biological activity studies}

\subsubsection{Antioxidant activity}

The antioxidant activity of complexes 1-5 was evaluated via their ability to scavenge DPPH, hydroxyl and ABTS radicals and to inhibit soybean lipoxygenase. Each experiment was performed in triplicate and the standard deviation of absorbance was less than $10 \%$ of the mean.

Determination of the reducing activity of the stable radical DPPH: To an ethanolic solution of DPPH (0.1 mM) an equal volume of the compounds dissolved in absolute ethanol was added. The concentration of the solution of the compounds was $0.1 \mathrm{mM}$. Ethanol was also used as 
control solution. The absorbance at $517 \mathrm{~nm}$ was recorded at room temperature, after 20 and $60 \mathrm{~min}$ in order to examine the time-dependence of the DPPH radical scavenging activity [51]. The DPPH radical scavenging activity of the compounds was expressed as the percentage reduction of the absorbance values of the initial DPPH solution (RA\%). NDGA and BHT were used as reference compounds.

Competition of the tested compounds with DMSO for hydroxyl radicals: The hydroxyl radicals generated by the $\mathrm{Fe}^{3+}$ /ascorbic acid system, were detected according to Nash [52], by the determination of formaldehyde produced from the oxidation of DMSO. The reaction mixture contained EDTA (0.1 mM), $\mathrm{Fe}^{3+}(167 \mu \mathrm{M})$, DMSO (33 mM) in phosphate buffer (50 mM, pH 7.4), the tested compounds (concentration $0.1 \mathrm{mM}$ ) and ascorbic acid (10 mM). After $30 \mathrm{~min}$ of incubation $\left(37^{\circ} \mathrm{C}\right)$ the reaction was stopped with $\mathrm{CCl}_{3} \mathrm{COOH}(17 \% \mathrm{w} / \mathrm{v})$ and the absorbance at $\lambda=$ $412 \mathrm{~nm}$ was measured. Trolox was used as an appropriate standard. The competition of the compounds with DMSO for ${ }^{\circ} \mathrm{OH}$, generated by the $\mathrm{Fe}^{3+} /$ ascorbic acid system, expressed as percent inhibition of formaldehyde production, was used for the evaluation of their hydroxyl radical scavenging activity ( $\left.{ }^{\circ} \mathrm{OH} \%\right)$.

Assay of radical cation scavenging activity: ABTS was dissolved in water to form a $2 \mathrm{mM}$ solution. ABTS radical cation $\left(\mathrm{ABTS}^{+\bullet}\right)$ was produced by reacting ABTS stock solution with 0.17 $\mathrm{mM}$ potassium persulfate and allowing the mixture to stand in the dark at room temperature for 12$16 \mathrm{~h}$ before use. Because ABTS and potassium persulfate react stoichiometrically at a ratio of 1:0.5, this will result in incomplete oxidation of the ABTS. Although the oxidation of the ABTS commenced immediately, the absorbance became maximal and stable after $6 \mathrm{~h}$. The radical was stable in this form for more than 2 days, when stored in the dark at room temperature. The ABTS ${ }^{+}$ solution was diluted with ethanol to an absorbance of 0.70 at $734 \mathrm{~nm}$. After addition of $10 \mu \mathrm{L}$ of diluted compounds or standards $(0.1 \mathrm{mM})$ in DMSO, the absorbance reading was taken exactly 1 min after initial mixing [51]. The radical scavenging activity of the complexes was expressed as the percentage inhibition of the absorbance of the initial ABTS solution (ABTS\%). Trolox was used as an appropriate standard.

Soybean lipoxygenase inhibition study in vitro: The in vitro study was evaluated as reported previously [51]. The tested compounds dissolved in ethanol were incubated at room temperature with sodium linoleate $(0.1 \mathrm{mM})$ and $0.2 \mathrm{~mL}$ of enzyme solution $\left(1 / 9 \times 10^{-4} \mathrm{w} / \mathrm{v}\right.$ in saline). The conversion of sodium linoleate to 13-hydroperoxylinoleic acid at $234 \mathrm{~nm}$ was recorded and compared with the appropriate standard inhibitor caffeic acid. 


\subsubsection{Albumin binding studies}

The albumin binding study was performed by tryptophan fluorescence quenching experiments using bovine (BSA, $3 \mu \mathrm{M}$ ) or human serum albumin (HSA, $3 \mu \mathrm{M}$ ) in buffer (containing $15 \mathrm{mM}$ trisodium citrate and $150 \mathrm{mM} \mathrm{NaCl}$ at $\mathrm{pH}$ 7.0). The quenching of the emission intensity of tryptophan residues of BSA at $343 \mathrm{~nm}$ or HSA at $351 \mathrm{~nm}$ was monitored using complexes 1-5 as quenchers with increasing concentration [53]. Fluorescence spectra were recorded in the range 300-500 nm with excitation wavelength of $295 \mathrm{~nm}$. The fluorescence emission spectra of the free complexes were also recorded under the same experimental conditions, i.e. excitation at $295 \mathrm{~nm}$, and exhibited a maximum emission at $415 \mathrm{~nm}$ [12]. Thus, the quantitative studies of the serum albumin fluorescence spectra were performed after correction by subtracting the spectra of the compounds. The influence of the inner-filter effect [54] on the measurements was evaluated by eq. S1. The Stern-Volmer and Scatchard equations (eq. S2-S4) and graphs [55] were used in order

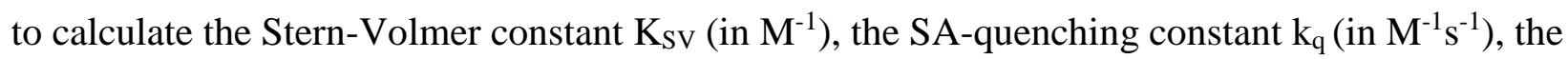
SA-binding constant $\mathrm{K}$ (in $\mathrm{M}^{-1}$ ) and the number of binding sites per albumin $\mathrm{n}$.

\subsubsection{DNA binding studies}

The interaction of complexes 1-5 with CT DNA has been studied by UV spectroscopy in order to investigate the possible binding modes to CT DNA and to calculate the DNA-binding constants $\left(\mathrm{K}_{\mathrm{b}}\right)$. The UV spectra of CT DNA (0.12-0.15 mM) were recorded in the presence of each compound at diverse [complex]/[DNA] mixing ratios $(=r)$. The values of $\mathrm{K}_{\mathrm{b}}\left(\right.$ in $\left.\mathrm{M}^{-1}\right)$ were determined by the Wolfe-Shimer equation (eq. S5) [56] and the plots [DNA]/( $\left.\varepsilon_{\mathrm{A}}-\varepsilon_{\mathrm{f}}\right)$ versus [DNA] using the UV spectra of the compound $(10-50 \mu \mathrm{M})$ recorded in the presence of DNA for diverse $r$ values. Control experiments with DMSO were performed and no changes in the spectra of CT DNA were observed.

The viscosity of DNA ([DNA] $=0.1 \mathrm{mM})$ in buffer solution $(150 \mathrm{mM} \mathrm{NaCl}$ and $15 \mathrm{mM}$ trisodium citrate at $\mathrm{pH}$ 7.0) was measured in the presence of increasing amounts of complexes 1-5 (up to the value of $\mathrm{r}=0.35$ ). All measurements were performed at room temperature. The obtained data are presented as $\left(\eta / \eta_{0}\right)^{1 / 3}$ versus $r$, where $\eta$ is the viscosity of DNA in the presence of the compound, and $\eta_{0}$ is the viscosity of DNA alone in buffer solution.

The competitive studies of complexes 1-5 with EB were investigated by fluorescence spectroscopy in order to examine whether the complex can displace EB from its CT DNA-EB conjugate. The CT DNA-EB conjugate was prepared by adding $20 \mu \mathrm{M}$ EB and $26 \mu \mathrm{M}$ CT DNA in buffer (150 mM NaCl and $15 \mathrm{mM}$ trisodium citrate at $\mathrm{pH}$ 7.0). The intercalating effect of the 
complexes was studied by adding stepwise a certain amount of a solution of the compound into a solution of the DNA-EB conjugate. The influence of the addition of each compound to the DNAEB complex solution was obtained by recording the changes of fluorescence emission spectra with excitation wavelength $\left(\lambda_{\mathrm{ex}}\right)$ at $540 \mathrm{~nm}$. Complexes 1-5 do not show any fluorescence emission bands at room temperature in solution or in the presence of DNA or EB under the same experimental conditions ( $\lambda_{\mathrm{ex}}=540 \mathrm{~nm}$ ); therefore, the observed quenching is attributed to the displacement of EB from its EB-DNA conjugate. The Stern-Volmer constants ( $\mathrm{K}_{\mathrm{sv}}$, in $\left.\mathrm{M}^{-1}\right)$ have been calculated according to the linear Stern-Volmer equation (eq. S2) [57] and the plots Io/I versus [Q]. Taking $\tau_{0}=23 \mathrm{~ns}$ as the fluorescence lifetime of the EB-DNA system [58], the quenching constants $\left(\mathrm{k}_{\mathrm{q}}, \mathrm{M}^{-1} \mathrm{~s}^{-1}\right)$ of the complexes were calculated according to eq. S3.

\subsection{Computational methods}

\subsubsection{Molecular docking studies}

Molecular docking [59] is a key tool in structural biology and computer aided drug design. The major goal of ligand-protein docking is to evaluate the feasible binding geometries of a putative ligand with a target protein of known three-dimensional structure.

To study the interactions of Hdifl and its complexes 1-5, we performed molecular docking studies using the Glide program (version 7.0, Schrödinger, LLC, New York, 2016) [60]. To analyze the docking results and execute the protocol, the Maestro user interface (version 10.5, Schrödinger, LLC, New York, 2016) was employed [61]. Docking was performed using at first the SP (Standard Precision Mode) and then the XP (Extra Precision Mode) protocol.

\subsubsection{Energy minimization of the protein}

The structure of HSA in complex with Hdifl was obtained from the Protein Data Bank code 2BXE. We used PDB code 4OR0 as a starting structure of BSA. This structure was in complex with naproxen. For CT DNA we used a synthetic DNA dodecamer (1BNA). All structures were imported and prepared by a multistep process through the protein preparation wizard of Maestro. Prior to protein preparation we excluded the Hdifl and naproxen that were in complex with HSA and BSA, respectively, and kept only one chain. We used the following procedure for all three biomacromolecules. 
The protocol was especially used to obtain the optimized and minimized energy conformation of the protein. First, we assigned bond orders and added hydrogen atoms. Water molecules which did not participate in interactions were removed. Following the above steps of preparation, the protein was subjected to energy minimization using Schrodinger implementation of OPLS3 force field.

\subsubsection{Energy minimization of the compounds}

Complexes 1-5 and Hdifl were built in 3D coordinates, were minimized in Macromodel to obtain the lowest energy conformation, retaining the geometry, and were prepared using the LigPrep 3.7 module of the Schrodinger suite using the standard protocol with OPLS3 force field.

\subsubsection{Active site prediction}

We employed Sitemap (version 3.8) [62] to search for potential binding sites. Sitemap applies theoretical methods and predicts the most accurate binding site. The OPLS3 force field generates site points, possible for ligand interaction within the protein. Sitemap gives an idea about positions favorable for a donor, acceptor, and hydrophobic group to be present in the receptor. Also we can obtain the active site volume, surface area, and character of binding sites of the receptor. We used Sitemap to identify the top-ranked potential receptor binding sites keeping all parameters as default, except for using a more restrictive definition of hydrophobicity and a fine grid. For each molecule, up to five sites with different site scores were obtained as output and the site with the highest score (SiteScore) was selected for CT DNA, while for both albumins we chose the two best binding sites.

We again used Sitemap after we had docked our ligands to evaluate the binding site, based on the druggability score (Dscore). Druggability is a term used in drug discovery to describe a biological target that is known to or is predicted to bind with high affinity to a drug. If that score is higher than 0.75 , the target is considered to be druggable [63].

\subsubsection{Grid generation - docking calculation}

We used the set of site points from the proposed binding site to generate a grid box for the docking calculation. We defined the grid box center according to our ligand each time. Then we performed a flexible docking calculation using the "Standard Precision" Glide algorithm and after 
the post-docking minimization we kept the pose with the best docking score and re-docked using the XP mode for higher accuracy. It should be noted that in order to compare the binding affinities and study possible interactions, we docked all five complexes as well as free diflunisal in the proposed binding sites of HSA, BSA and CT DNA.

\section{Results and discussion}

\subsection{Synthesis of the complexes}

The synthesis of the complexes in high yield was achieved via the aerobic reaction of diflunisal and $\mathrm{KOH}$ with $\mathrm{ZnCl}_{2}$ in the absence or presence of the corresponding $\mathrm{N}, \mathrm{N}^{\prime}$-donor heterocyclic ligand (bipyam, bipy, phen or Hpko).

A 1:2 $\mathrm{Zn}^{2+}:$ difl $^{-1}$ ratio yielded complex $\mathbf{1}$, complexes $\mathbf{2 - 4}$ were prepared using a 1:2:1 $\mathrm{Zn}^{2+}:$ difl $^{-1}: \mathrm{N}, \mathrm{N}^{\prime}$-donor (bipyam, bipy or phen) ratio while a $1: 2: 2 \mathrm{Zn}^{2+}:$ difl $^{-1}:$ Hpko afforded complex 5. The complexes were characterized by elemental analysis, IR, ${ }^{1} \mathrm{H}-\mathrm{NMR}$ and UV-vis spectroscopic techniques and by X-ray crystallography (in the case of complexes 2, 3 and 5).

Complex 1 possesses a 1:2 Zn:difl composition, while for complexes 2-5 an 1:2:1 (2-4) or 1:2:2 (5) Zn:difl:N,N'-donor composition is expected, as it is indicated from elemental analysis. The complexes are stable in air, soluble in DMSO and DMF but insoluble in most organic solvents and $\mathrm{H}_{2} \mathrm{O}$. According to the molar conductivity values $\left(\Lambda_{\mathrm{M}}\right)$, the complexes are non-electrolytes in $\operatorname{DMSO}\left(\Lambda_{\mathrm{M}}=6-10 \mathrm{~S} \cdot \mathrm{cm}^{2} \cdot \mathrm{mol}^{-1}\right.$, in $1 \mathrm{mM}$ DMSO solution); thus, we may consider that the compounds remain stable and do not dissociate in DMSO solution.

\subsection{Spectroscopic characterization of the complexes}

The spectroscopic characterization of complexes 1-5 has been performed by IR, ${ }^{1} \mathrm{H}-\mathrm{NMR}$ and UV-vis spectroscopies.

The deprotonation and the binding mode of diflunisal in the complexes and the co-existence of the N,N'-donors in complexes 2-5 was initially confirmed by IR spectroscopy [64]. The absorption band at 3436(broad, m) $\mathrm{cm}^{-1}$ in the IR spectrum of Hdifl which assigned to the $v(\mathrm{O}-\mathrm{H})$ stretching vibration of Hdifl disappeared in the IR spectra of the complexes, revealing, thus, the deprotonation of the carboxylato group of diflunisal [12]. Additionally, the bands assigned to the $v(\mathrm{C}=\mathrm{O})_{\text {carboxylic }}$ and $v(\mathrm{C}-\mathrm{O})_{\text {carboxylic }}$ stretching vibrations of the carboxylic moiety (-COOH) of Hdifl located in the IR spectrum of Hdifl at 1689(s) $\mathrm{cm}^{-1}$ and 1269(s) $\mathrm{cm}^{-1}$, respectively, shifted in the IR 
spectra of complexes 1-5 in the range of $1587-1598 \mathrm{~cm}^{-1}$ and $1374-1397 \mathrm{~cm}^{-1}$ being assigned to antisymmetric $\left[v_{\text {asym }}\left(\mathrm{CO}_{2}\right)\right]$ and symmetric $\left[v_{\text {sym }}\left(\mathrm{CO}_{2}\right)\right]$ stretching vibrations, respectively, of the carboxylato group [64]. In the case of carboxylato ligands, a useful tool to examine their coordination mode is the parameter $\Delta v\left(\mathrm{CO}_{2}\right)\left(=v_{\text {asym }}\left(\mathrm{CO}_{2}\right)-v_{\text {sym }}\left(\mathrm{CO}_{2}\right)\right.$ [64]. For complexes $\mathbf{1}$ and $\mathbf{5}$, $\Delta v\left(\mathrm{CO}_{2}\right)$ is calculated in the range $210-224 \mathrm{~cm}^{-1}$, implying a monodentate binding mode of the carboxylato group of diflunisal [12,13,65]; for complexes 2-4, the calculated $\Delta v\left(\mathrm{CO}_{2}\right)$ values were in the range 192-195 $\mathrm{cm}^{-1}$, suggesting rather the existence of a bidentate chelating coordination mode $[64,65]$. These findings regarding the $\Delta v\left(\mathrm{CO}_{2}\right)$ values are in good agreement with the structures of the complexes determined by X-ray crystallography. Additionally, in the IR spectra of complexes 2-5, characteristic bands of the out-of-plane $\rho(\mathrm{C}-\mathrm{H})$ vibrations of the corresponding $\mathrm{N}, \mathrm{N}^{\prime}$-donor were observed: the $\rho(\mathrm{C}-\mathrm{H})_{\text {bipyam }}$ was located at $763(\mathrm{~m}) \mathrm{cm}^{-1}$ in 2 , the $\rho(\mathrm{C}-\mathrm{H})_{\text {bipy }}$ at 764(m) $\mathrm{cm}^{-1}$ in 3, the $\rho(\mathrm{C}-\mathrm{H})_{\text {phen }}$ at $726(\mathrm{~m}) \mathrm{cm}^{-1}$ in 4 and the $\rho(\mathrm{C}-\mathrm{H})_{\mathrm{Hpko}} 785(\mathrm{~m}) \mathrm{cm}^{-1}$ in 5, confirming the existence and the coordination of the corresponding $\mathrm{N}, \mathrm{N}^{\prime}$-donor ligands in the complexes [64].

${ }^{1} \mathrm{H}-\mathrm{NMR}$ spectroscopy was used in order to monitor the behavior of the complexes in solution. The ${ }^{1} \mathrm{H}-\mathrm{NMR}$ spectra of the complexes were recorded in DMSO- $\mathrm{d}_{6}$ solution and verifying the proposed formulae of the complexes, their purity and their integrity in solution. In the ${ }^{1} \mathrm{H}-\mathrm{NMR}$ spectra of the complexes (representative spectra are shown in Fig. S1), the absence of a signal at 11.97 ppm assigned to carboxylic hydrogen of the free diflunisal may confirm the deprotonated mode of the bound NSAID. The other signals of the diflunisal are present and are slightly shifted downfield or upfield as anticipated upon coordination to Zn(II) ion [17,18,35,36]. Furthermore, the signals related to the existence of the $\mathrm{N}, \mathrm{N}^{\prime}$-donor ligands are present as anticipated and the ratios of integrated peaks confirm the ratio of ligands (diflunisal:N,N'-donors) in the solid state. Any additional signals that might be assigned to dissociated ligands were not observed; this may suggest that the complexes remain intact in solution [27,28,66,67], being in agreement with the molar conductance measurements.

The UV-vis spectra of the complexes were recorded as nujol mull and in DMSO solution and were similar indicating that the compounds retain their structure in solution. Additionally, no significant changes (shift of the $\lambda_{\max }$ or new peaks) were observed in the UV-Vis spectra of the complexes in DMSO solution in the presence of diverse buffer solutions $(150 \mathrm{mM} \mathrm{NaCl}$ and 15 $\mathrm{mM}$ trisodium citrate) in the $\mathrm{pH}$ range 6-8 (regulated by $\mathrm{HCl}$ solution) as used in the biological studies, confirming that the complexes keep their integrity in the $\mathrm{pH}$ range 6-8 $[27,28]$.

Therefore, from the fact that complexes 1-5 are non-electrolytes in DMSO solution, bearing similar UV-vis spectra in nujol, in DMSO solution and in the presence of the buffer solutions, and 
that the ${ }^{1} \mathrm{H}-\mathrm{NMR}$ spectra do not show any new species, we may conclude that the complexes are stable keeping their integrity in solution.

\subsection{Structure of the complexes}

\subsubsection{Crystal structure of $\left[\mathrm{Zn}(\text { difl-O,O' })_{2}(\right.$ bipyam $\left.)\right] \cdot \mathrm{MeOH}, 2 \cdot \mathrm{MeOH}$}

The molecular structure of complex [Zn(difl-O,O') $)_{2}$ (bipyam)], 2, is shown in Fig. 2, and selected bond distances and angles are listed in Table 1. The lattice methanol solvents are not shown in this figure. The structure of complex 2 consists of a $\mathrm{Zn}^{\mathrm{II}}$ ion bound to two deprotonated diflunisal ligands and one bipyam ligand. Each diflunisal ligand is coordinated through the carboxylato group whilst the hydroxyl group remains protonated and stands away from the coordination sphere of the metal ion. The carboxylato group of each diflunisal ligand is coordinated to zinc in an asymmetric bidentate chelating mode $(\mathrm{Zn}-\mathrm{O}(1)=2.006(2)$, $\mathrm{Zn}-\mathrm{O}(2)=2.467(2)$, Zn$\mathrm{O}(22)=1.966(2), \mathrm{Zn}-\mathrm{O}(21)=2.768(2) \AA \AA)$. Large $\mathrm{Zn}-\mathrm{O}$ distances in the range 2.7-2.8 $\AA$ have been previously considered as bonding in analogous $\mathrm{ZnN}_{2} \mathrm{O}_{4}$ complexes with chelating bidentate carboxylato or nitrato groups [68-71]. The geometry around the zinc ion is best described as severely distorted octahedral due to the acute O-Zn-O bite angles $\left(57.47(7)^{\circ}\right.$ and $\left.52.44(6)^{\circ}\right)$ of the two chelating carboxylato groups of the diflunisal ligands. The fluoro-substituted aromatic ring of diflunisal ligands is twisted around the $\mathrm{C}-\mathrm{C}$ bond with respect to the salicylato aromatic ring at $57.1^{\circ}$ and $27.5^{\circ}$, for the ligands defined by $\mathrm{O}(1)$ and $\mathrm{O}(21)$, respectively.

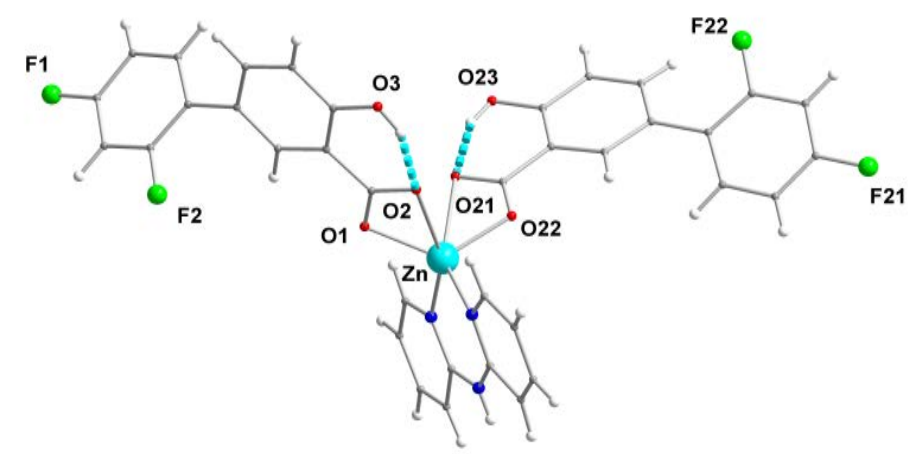

Fig. 2. Partially labeled plot of the molecular structure of complex 2. Cyan dashed lines indicate the intramolecular $\mathrm{O}(3)-\mathrm{H}(3 \mathrm{O}) \ldots \mathrm{O}(2)$ and $\mathrm{O}(23)-\mathrm{H}(23 \mathrm{O}) \ldots \mathrm{O}(21)$ hydrogen bonds.

Table 1. Selected bond distances and angles for complex 2.

\begin{tabular}{llll}
\hline Bond & Distance $(\AA)$ & Bond & Distance $(\AA)$
\end{tabular}




\begin{tabular}{lclc}
\hline $\mathrm{Zn}-\mathrm{O}(1)$ & $2.006(2)$ & $\mathrm{Zn}-\mathrm{O}(22)$ & $1.966(2)$ \\
$\mathrm{Zn}-\mathrm{O}(2)$ & $2.467(2)$ & $\mathrm{Zn}-\mathrm{N}(1)$ & $2.045(2)$ \\
$\mathrm{Zn}-\mathrm{O}(21)$ & $2.768(2)$ & $\mathrm{Zn}-\mathrm{N}(2)$ & $2.030(2)$ \\
$\mathrm{C}(1)-\mathrm{O}(1)$ & $1.276(3)$ & $\mathrm{C}(21)-\mathrm{O}(21)$ & $1.256(3)$ \\
$\mathrm{C}(1)-\mathrm{O}(2)$ & $1.251(3)$ & $\mathrm{C}(21)-\mathrm{O}(22)$ & $1.266(3)$ \\
\hline Bond angle & $\left({ }^{\circ}\right)$ & $\mathrm{Bond}$ angle & $\left({ }^{\circ}\right)$ \\
\hline $\mathrm{O}(1)-\mathrm{Zn}-\mathrm{O}(2)$ & $57.74(7)$ & $\mathrm{O}(2)-\mathrm{Zn}-\mathrm{O}(21)$ & $92.54(6)$ \\
$\mathrm{O}(1)-\mathrm{Zn}-\mathrm{O}(21)$ & $83.00(7)$ & $\mathrm{O}(2)-\mathrm{Zn}-\mathrm{O}(22)$ & $91.52(7)$ \\
$\mathrm{O}(1)-\mathrm{Zn}-\mathrm{O}(22)$ & $125.87(7)$ & $\mathrm{O}(2)-\mathrm{Zn}-\mathrm{N}(1)$ & $157.34(7)$ \\
$\mathrm{O}(1)-\mathrm{Zn}-\mathrm{N}(1)$ & $100.45(8)$ & $\mathrm{O}(2)-\mathrm{Zn}-\mathrm{N}(2)$ & $93.61(7)$ \\
$\mathrm{O}(1)-\mathrm{Zn}-\mathrm{N}(2)$ & $121.45(7)$ & $\mathrm{O}(22)-\mathrm{Zn}-\mathrm{N}(1)$ & $107.95(8)$ \\
$\mathrm{O}(21)-\mathrm{Zn}-\mathrm{O}(22)$ & $52.44(6)$ & $\mathrm{O}(22)-\mathrm{Zn}-\mathrm{N}(2)$ & $101.98(7)$ \\
$\mathrm{O}(21)-\mathrm{Zn}-\mathrm{N}(1)$ & $90.44(7)$ & $\mathrm{N}(1)-\mathrm{Zn}-\mathrm{N}(2)$ & $93.54(8)$ \\
$\mathrm{O}(21)-\mathrm{Zn}-\mathrm{N}(2)$ & $153.86(7)$ & & \\
\hline
\end{tabular}

In the crystal structure of complex 2, intra-ligand hydrogen-bonds are observed between the phenolic hydrogen atoms $\mathrm{H}(3 \mathrm{O})$ and $\mathrm{H}(23 \mathrm{O})$ and the carboxylato oxygen atoms $\mathrm{O}(2)$ and $\mathrm{O}(21)$, respectively, of diflunisal ligands (Table S2, Fig. 2). The $\pi$ - $\pi$ overlap of bipyam ligands (with a centroid-to-centroid distance equal to $3.623 \AA$ ) belonging to neighboring clusters results in dimer formation which further interact through methanol molecules with the $\mathrm{O}(\mathrm{M})-\mathrm{H}(\mathrm{OM}) \ldots \mathrm{O}(1)$ and $\mathrm{N}(3)-\mathrm{H}(3 \mathrm{~N}) . . . \mathrm{O}(\mathrm{M})$ ' hydrogen bonds (Table S2, Fig. S2). Neighboring dimers interact through C47-H47...O23 hydrogen bonds and form chains parallel to the [110] crystallographic direction (Table S2, Fig. S2). These chains interact through $\mathrm{O}(3)-\mathrm{H}(30) . . \mathrm{O}(22)$ hydrogen bonds and form layers parallel to the (001) crystallographic plane (Table S2, Fig. S3).

\subsubsection{Crystal structure of [Zn(difl-O,O')2(bipy)], 3}

A drawing of the molecular structure of [Zn(difl-O,O') $)_{2}($ bipy)], 3, is shown in Fig. 3 and selected bond distances and angles are given in Table 2. The coordination around the zinc ion in $\mathbf{3}$ is 
similar to 2 described above and consists of two chelating bidentate carboxylato groups from two diflunisal ligands and the two nitrogen atoms of the bipy. The coordination geometry is severely distorted from the ideal octahedron due to the acute O-Zn-O angles of the chelating bidentate carboxylato groups (55.86(7) and 54.89(7) ${ }^{\circ}$ ). The Zn-O distances indicate asymmetric coordination of the carboxylato oxygen atoms as in complex $2(\mathrm{Zn}(1)-\mathrm{O}(1)=1.962(2), \mathrm{Zn}(1)-\mathrm{O}(2)=2.596(2)$, $\mathrm{Zn}(1)-\mathrm{O}(22)=1.947(2), \mathrm{Zn}(1)-\mathrm{O}(21)=2.667(2) \AA)$. The fluoro-substituted aromatic ring of diflunisal ligands is twisted around the C-C bond with respect to the salicylato aromatic ring at 36.4 and $43.4^{\circ}$, for the ligands defined by $\mathrm{O}(1)$ and $\mathrm{O}(21)$, respectively.

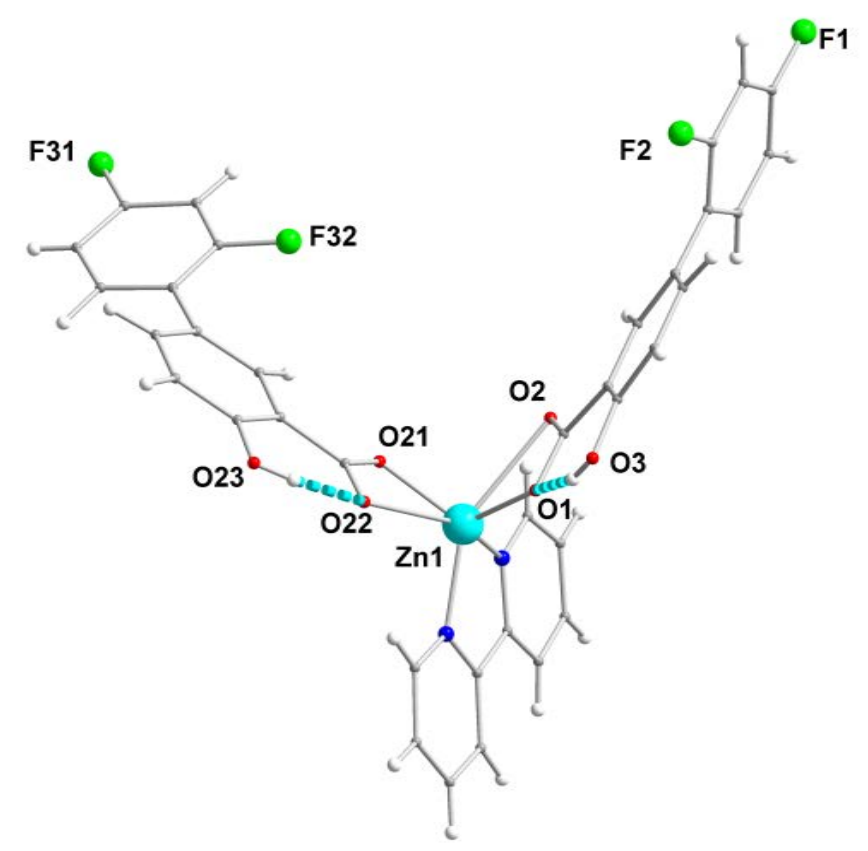

Fig. 3. Partially labeled plot of the molecular structure of complex 3. Cyan dashed lines indicate the intramolecular $\mathrm{O}(3)-\mathrm{H}(3 \mathrm{O}) \ldots \mathrm{O}(21)$ and $\mathrm{O}(23)-\mathrm{H}(23 \mathrm{O}) \ldots \mathrm{O}(21)$ hydrogen bonds.

Table 2. Selected bond distances and angles for complex 3.

\begin{tabular}{llll}
\hline Bond & Distance $(\AA)$ & Bond & Distance (A) \\
\hline $\mathrm{Zn}(1)-\mathrm{O}(1)$ & $1.962(2)$ & $\mathrm{Zn}(1)-\mathrm{O}(22)$ & $1.947(2)$ \\
$\mathrm{Zn}(1)-\mathrm{O}(2)$ & $2.596(2)$ & $\mathrm{Zn}(1)-\mathrm{N}(41)$ & $2.063(2)$ \\
$\mathrm{Zn}(1)-\mathrm{O}(21)$ & $2.667(2)$ & $\mathrm{Zn}(1)-\mathrm{N}(42)$ & $2.066(2)$ \\
$\mathrm{C}(1)-\mathrm{O}(1)$ & $1.301(3)$ & $\mathrm{C}(21)-\mathrm{O}(21)$ & $1.257(3)$ \\
$\mathrm{C}(1)-\mathrm{O}(2)$ & $1.229(3)$ & $\mathrm{C}(21)-\mathrm{O}(22)$ & $1.278(3)$ \\
\hline
\end{tabular}




\begin{tabular}{llll}
\hline Bond angle & $\mathbf{(}^{\circ}$ & Bond angle & $\mathbf{(}^{\circ}$ \\
\hline $\mathrm{O}(1)-\mathrm{Zn}(1)-\mathrm{O}(2)$ & $55.86(7)$ & $\mathrm{O}(2)-\mathrm{Zn}(1)-\mathrm{O}(21)$ & $116.12(6)$ \\
$\mathrm{O}(1)-\mathrm{Zn}(1)-\mathrm{O}(21)$ & $88.16(7)$ & $\mathrm{O}(2)-\mathrm{Zn}(1)-\mathrm{O}(22)$ & $91.75(7)$ \\
$\mathrm{O}(1)-\mathrm{Zn}(1)-\mathrm{O}(22)$ & $114.87(8)$ & $\mathrm{O}(2)-\mathrm{Zn}(1)-\mathrm{N}(41)$ & $81.59(7)$ \\
$\mathrm{O}(1)-\mathrm{Zn}(1)-\mathrm{N}(41)$ & $115.39(8)$ & $\mathrm{O}(2)-\mathrm{Zn}(1)-\mathrm{N}(42)$ & $148.88(7)$ \\
$\mathrm{O}(1)-\mathrm{Zn}(1)-\mathrm{N}(42)$ & $111.78(7)$ & $\mathrm{O}(22)-\mathrm{Zn}(1)-\mathrm{N}(41)$ & $112.22(8)$ \\
$\mathrm{O}(21)-\mathrm{Zn}(1)-\mathrm{O}(22)$ & $54.89(7)$ & $\mathrm{O}(22)-\mathrm{Zn}(1)-\mathrm{N}(42)$ & $118.31(8)$ \\
$\mathrm{O}(21)-\mathrm{Zn}(1)-\mathrm{N}(41)$ & $156.33(7)$ & $\mathrm{N}(41)-\mathrm{Zn}(1)-\mathrm{N}(42)$ & $79.66(8)$ \\
$\mathrm{O}(21)-\mathrm{Zn}(1)-\mathrm{N}(42)$ & $89.68(7)$ & & \\
\hline
\end{tabular}

Intra-cluster hydrogen bonds are developed between the salicylic hydrogen atom $\mathrm{H}(3 \mathrm{O})$ and the coordinated carboxylato oxygen atom $\mathrm{O}(1)$ of diflunisal ligand and the salicylic hydrogen atom $\mathrm{H}(23 \mathrm{O})$ and non-coordinated carboxylato oxygen atom $\mathrm{O}(21)$ of the other diflunisal ligand and contribute to further stabilization of the complex (Table S2). The clusters in $\mathbf{3}$ form chains parallel to the a crystallographic axis through the $\mathrm{C}(7)-\mathrm{H}(7) \ldots \mathrm{O}(1)$ and $\mathrm{H}(50)-\mathrm{O}(22) \ldots \mathrm{O}(22)$ hydrogen bonds (Table S2, Fig. S4). These chains interact through C(47)-H(47)...O(23) hydrogen bonds and form layers parallel to the (001) crystallographic plane (Table S2, Fig. S5). These chains are stabilized farther through the $\pi$ - $\pi$ overlap of bipy ligands (Fig. S5) belonging to neighboring clusters at neighboring chains (with a centroid-to-centroid distance equal to $3.770 \AA$ ).

\subsubsection{Crystal structure of $\left[\mathrm{Zn}(\text { difl-O })_{2}\left(\mathrm{Hpko}_{\mathbf{2}} \mathrm{N}, \mathrm{N}^{\prime}\right)_{2}\right], 5$}

A drawing of the molecular structure of [Zn(difl-O $\left.)_{2}\left(\mathrm{Hpko}-\mathrm{N}, \mathrm{N}^{\prime}\right)_{2}\right], 5$, is shown in Fig. 4 and selected bond distances and angles are cited in Table 3. 


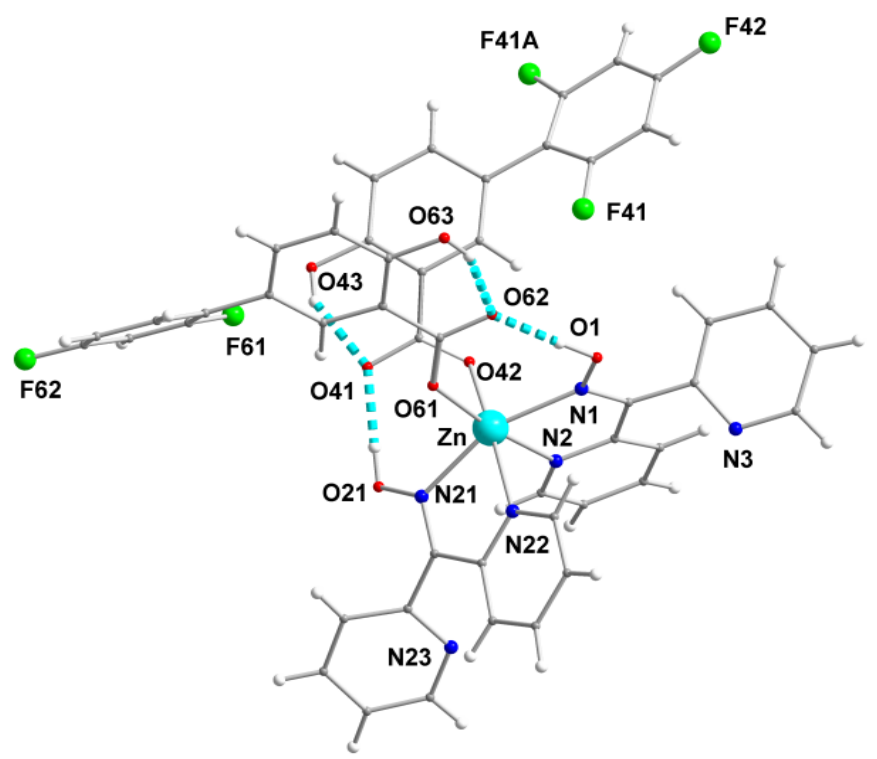

Fig. 4. Partially labeled plot of the molecular structure of complex 5. Cyan dashed lines indicate the intramolecular $\mathrm{O}(1)-\mathrm{H}(1 \mathrm{O}) \ldots \mathrm{O}(62), \mathrm{O}(63)-\mathrm{O}(63 \mathrm{O}) \ldots \mathrm{O}(62), \mathrm{O}(21)-\mathrm{H}(21 \mathrm{O}) \ldots \mathrm{O}(41)$ and $\mathrm{O}(43)-$ $\mathrm{H}(43 \mathrm{O})$... $\mathrm{O}(41)$ hydrogen bonds.

Table 3. Selected bond distances and angles for complex 5.

\begin{tabular}{|c|c|c|c|}
\hline Bond & Distance $(\AA)$ & Bond & Distance $(\AA)$ \\
\hline $\mathrm{Zn}-\mathrm{O}(42)$ & $2.014(2)$ & $\mathrm{Zn}-\mathrm{N}(2)$ & $2.247(2)$ \\
\hline $\mathrm{Zn}-\mathrm{O}(61)$ & $2.068(1)$ & $\mathrm{Zn}-\mathrm{N}(21)$ & $2.178(2)$ \\
\hline $\mathrm{Zn}-\mathrm{N}(1)$ & $2.162(2)$ & $\mathrm{Zn}-\mathrm{N}(22)$ & $2.140(2)$ \\
\hline $\mathrm{C}(41)-\mathrm{O}(41)$ & $1.265(3)$ & $\mathrm{C}(61)-\mathrm{O}(61)$ & $1.255(2)$ \\
\hline $\mathrm{C}(41)-\mathrm{O}(42)$ & $1.258(2)$ & $\mathrm{C}(61)-\mathrm{O}(62)$ & $1.270(2)$ \\
\hline Bond angle & $\left({ }^{\circ}\right)$ & Bond angle & $\left({ }^{\circ}\right)$ \\
\hline $\mathrm{O}(42)-\mathrm{Zn}-\mathrm{O}(61)$ & $90.82(6)$ & $\mathrm{O}(61)-\mathrm{Zn}-\mathrm{N}(1)$ & 102.62(6) \\
\hline $\mathrm{O}(42)-\mathrm{Zn}-\mathrm{N}(1)$ & $94.33(7)$ & $\mathrm{O}(61)-\mathrm{Zn}-\mathrm{N}(2)$ & $172.38(6)$ \\
\hline $\mathrm{O}(42)-\mathrm{Zn}-\mathrm{N}(2)$ & $82.87(6)$ & $\mathrm{O}(61)-\mathrm{Zn}-\mathrm{N}(21)$ & $95.55(6)$ \\
\hline $\mathrm{O}(42)-\mathrm{Zn}-\mathrm{N}(21)$ & $96.75(6)$ & $\mathrm{O}(61)-\mathrm{Zn}-\mathrm{N}(22)$ & $98.85(6)$ \\
\hline $\mathrm{O}(42)-\mathrm{Zn}-\mathrm{N}(22)$ & $167.74(6)$ & $\mathrm{N}(2)-\mathrm{Zn}-\mathrm{N}(21)$ & $89.47(6)$ \\
\hline
\end{tabular}




$\begin{array}{llll}\mathrm{N}(1)-Z n-\mathrm{N}(2) & 73.72(6) & \mathrm{N}(2)-Z n-\mathrm{N}(22) & 87.98(6) \\ \mathrm{N}(1)-Z n-\mathrm{N}(21) & 158.54(6) & \mathrm{N}(21)-\mathrm{Zn}-\mathrm{N}(22) & 74.93(6) \\ \mathrm{N}(1)-Z n-\mathrm{N}(22) & 90.92(6) & & \end{array}$

In mononuclear complex $5, \mathrm{Zn}$ (II) is six-coordinate with a $\mathrm{ZnN}_{4} \mathrm{O}_{2}$ chromophore and is surrounded by two diflunisal ligands and two Hpko showing a distorted octahedral environment (the trans angles around zinc are in the range $\left.158.54(6)^{\circ}-172.38(6)^{\circ}\right)$. The vertices of the octahedron are occupied by two oxygen atoms of the diflunisal ligands and four nitrogen atoms of the Hpko ligands. The Zn-O bond distances (= 2.014(2) - 2.068(1) Å) are much shorter than the Zn$\mathrm{N}$ bond distances $(=2.140(2)-2.247(2) \AA)$. These distances are in accordance to those previously reported in the zinc complexes with the NSAIDs mefenamic acid [Zn(mefenamato-O $)_{2}(\mathrm{Hpko})_{2}$ ] [27] and tolfenamic acid [Zn(tolfenamato-O) $\left.)_{2}(\text { Hpko })_{2}\right]$ [28].

The diflunisal ligands are simply deprotonated and behave as monodentate ligands being bound to zinc ion via a carboxylato oxygen. The carboxylate groups of the diflunisal ligands are monodentately bound to zinc in asymmetric fashion $(\mathrm{C}(41)-\mathrm{O}(41)=1.265(3) \AA$ and $\mathrm{C}(41)-\mathrm{O}(42)=$ 1.258(2) $\AA, \mathrm{C}(61)-\mathrm{O}(61)=1.255(2) \AA$ and $\mathrm{C}(61)-\mathrm{O}(62)=1.270(2) \AA)$. In regard to six-coordinate metal complexes bearing two monodentate salicylato derivatives as ligands and a $\mathrm{MN}_{4} \mathrm{O}_{2}$ chromophore included in the CCDC database, the salicylato ligands were located in cis positions $[72,73]$ similarly to complex 5, in few cases, and especially those bearing relatively robust N,N'donor co-ligands such as bipy and phen; for most of the reported complexes, the salicylato ligands were found in trans arrangement, especially in the co-existence of monodentate N-donors [74,75], flexible N,N'-donors [76,77] or planar N,N',N",N"'-donor porphyrinato derivatives [78]. The fluorosubstituted aromatic ring of diflunisal ligands is twisted around the $\mathrm{C}-\mathrm{C}$ bond with respect to the salicylato aromatic ring at 29.2 and $43.2^{\circ}$, for the ligands defined by $\mathrm{O}(41)$ and $\mathrm{O}(61)$, respectively.

The two Hpko ligands are neutral and are bound to zinc in a bidentate chelating mode via a pyridine nitrogen and the oxime nitrogen, while the ketoxime oxygen remains uncoordinated and are in (1.0110) coordination mode according to the Harris notation [79]. Such coordination mode was also found in mononuclear metal-NSAID complexes such as [Ni(mefenamato $)_{2}(\mathrm{Hpko})_{2}$ ] [42], [Zn(mefenamato $)_{2}(\text { Hpko })_{2}$ ] [27] and [Zn(tolfenamato $)_{2}(\text { Hpko })_{2}$ ] [28] among others. The coordinated pyridyl ring is twisted with respect to the unbound one at 72.7 and $62.4^{\circ}$, for the Hpko ligands defined by $\mathrm{N}(1)$ and $\mathrm{N}(21)$, respectively. 
The structure of the complex is further stabilized by intramolecular hydrogen bonds. In particular, the non-coordinated carboxylato oxygens $\mathrm{O}(41)$ and $\mathrm{O}(62)$ of the diflunisal ligands form intra-ligand hydrogen bonds with the salicylic hydrogen atoms $\mathrm{H}(43 \mathrm{O})$ and $\mathrm{H}(63 \mathrm{O})$ and with the ketoxime hydrogen atoms $\mathrm{H}(1 \mathrm{O})$ and $\mathrm{H}(210)$ of the Hpko ligands (Table S2, Fig. 4). The clusters in 5 form layers parallel to the (-101) crystallographic plane through a network of C(10)$\mathrm{H}(10) \ldots \mathrm{N}(23), \mathrm{C}(24)-\mathrm{H}(24) \ldots \mathrm{O}(63), \mathrm{C}(52)-\mathrm{H}(52) \ldots \mathrm{O}(1)$ and $\mathrm{C}(70)-\mathrm{H}(70) \cdots \mathrm{O}(21)$ hydrogen bonds (Table S2, Fig. S6).

\subsubsection{Proposed structures for complexes 1 and 4}

Based on the IR, UV-vis, ${ }^{1} \mathrm{H}$-NMR spectroscopy and elemental analysis data, complexes 1 and $\mathbf{4}$ are neutral mononuclear complexes. According to IR spectral data, the diflunsial ligands are deprotonated and are expected to be monodentately (in 1) or bidentately (in 4) bound to zinc ion in the complexes via carboxylato oxygen atoms. In $\mathbf{1}$, the zinc is six-coordinate in a distorted octahedral geometry with two oxygen atoms from the diflunisal ligands and four oxygen atoms from the methanol ligands occupying the vertices of the octahedron while complex $\mathbf{4}$ is expected to have similar structure and arrangement of the four oxygen atoms from the diflunisal ligands and two phen nitrogen atoms to that found in complexes $\mathbf{2}$ and $\mathbf{3}$.

\subsection{Antioxidant activity}

Free radicals are species having an important role in the inflammatory process. Compounds that can inhibit the free radical production and/or act as radical scavengers may have an important application to treat inflammation [80]. Within this context and bearing in mind that diflunisal is a potent NSAID, the ability of Zn(II)-diflunisal complexes 1-5 to scavenge in vitro DPPH, ABTS and hydroxyl radicals and to inhibit the activity of soybean lipoxygenase was monitored in comparison to well-known antioxidant agents used as standard reference compounds, such as NDGA, BHT, trolox and caffeic acid (Table 4). The radicals were selected based on their scavenging significance. More specifically, the scavenging of DDPH radicals is closely related to antiageing, anticancer and anti-inflammatory activity. The scavenging of hydroxyl radicals ( $\left.{ }^{\circ} \mathrm{OH}\right)$ may be related with compounds able to relief from the presence of reactive oxygen species. The scavenging of the cationic ABTS radicals $\left(\mathrm{ABTS}^{+\bullet}\right.$ ) is often related to the total antioxidant activity [51]. LOX inhibitors may be considered potential antioxidants or free radical scavengers since lipoxygenation is procedure usually occurring via a carbon centered radical [81]. 
Table 4. \% DPPH scavenging ability (RA\%), competition \%with DMSO for hydroxyl radical ( $\left.{ }^{\circ} \mathrm{OH} \%\right)$, \% superoxide radical scavenging activity (ABTS\%), and in vitro inhibition of soybean lipoxygenase (LOX, $\mathrm{IC}_{50}$ in $\mu \mathrm{M}$ ) for complexes 1-5.

\begin{tabular}{|c|c|c|c|c|c|}
\hline & RA\%, 20 min & RA\%, 60 min & ABTS\% & 'OH\% & LOX \\
\hline Hdifl & $10.42 \pm 0.56$ & $14.31 \pm 0.45$ & $76.58 \pm 0.74$ & $86.06 \pm 0.38$ & $32.43 \pm 1.32$ \\
\hline$\left[\mathrm{Zn}(\operatorname{difl})_{2}(\mathrm{MeOH})_{4}\right], \mathbf{1}$ & $22.37 \pm 0.41$ & $20.74 \pm 0.73$ & $89.73 \pm 1.31$ & $94.58 \pm 0.52$ & $22.78 \pm 0.39$ \\
\hline [Zn(difl) $)_{2}$ (bipyam)], 2 & $15.61 \pm 0.51$ & $17.68 \pm 0.55$ & $80.31 \pm 0.81$ & $85.64 \pm 0.78$ & $36.49 \pm 0.59$ \\
\hline [Zn(difl) $)_{2}($ bipy)], 3 & $18.52 \pm 0.60$ & $19.57 \pm 0.32$ & $90.42 \pm 0.82$ & $90.21 \pm 1.04$ & $27.56 \pm 0.82$ \\
\hline$\left[\mathrm{Zn}(\operatorname{difl})_{2}\right.$ (phen)], 4 & $12.73 \pm 0.49$ & $14.44 \pm 0.89$ & $96.48 \pm 0.79$ & $95.78 \pm 0.84$ & $18.92 \pm 0.48$ \\
\hline$\left[\mathrm{Zn}(\operatorname{difl})_{2}(\mathrm{Hpko})_{2}\right], 5$ & $14.87 \pm 0.92$ & $16.80 \pm 0.62$ & $75.47 \pm 0.52$ & $90.87 \pm 0.26$ & $29.74 \pm 1.02$ \\
\hline NDGA & $81.02 \pm 0.18$ & $82.60 \pm 0.17$ & not tested & not tested & not tested \\
\hline BHT & $31.30 \pm 0.10$ & $60.00 \pm 0.38$ & not tested & not tested & not tested \\
\hline Trolox & not tested & not tested & $91.80 \pm 0.17$ & $82.80 \pm 0.13$ & not tested \\
\hline Caffeic acid & not tested & not tested & not tested & not tested & $600 \pm 0.3$ \\
\hline
\end{tabular}

The Zn-diflunisal complexes 1-5 are more active scavengers of the DPPH, 'OH and ABTS ${ }^{+\bullet}$ radicals than the parent NSAID (Table 4). The DPPH scavenging activity of the complexes was time-independent and was found in the range 14.44-20.74\% and is lower than that of the reference compounds BHT and NDGA. Complex $\left[\mathrm{Zn}(\operatorname{difl})_{2}(\mathrm{MeOH})_{4}\right], 1$ shows the best DPPH-scavenging activity among the complexes. The scavenging ability of the complexes towards hydroxyl radicals is significantly high and all complexes $\mathbf{1 - 5}$ are even more active than the reference compound trolox and complex [Zn(difl) 2 (phen)], $\mathbf{4}$ is the best hydroxyl-scavenger. In regard to the ability of complexes 1-5 to scavenge ABTS radicals, the complexes are significantly active but less active than the reference compound trolox with the exception of [ $\left.\mathrm{Zn}(\mathrm{difl})_{2}(\mathrm{phen})\right], \mathbf{4}$ which is the best ABTS-scavenger among the Zn-diflunisal complexes. In comparison to the reference compound caffeic acid, all complexes are very active inhibitors of LOX with [Zn(difl)2(phen)], 4 being significantly more active than the rest Zn-diflunisal complexes. 
In general, the complexes are better radical scavengers than free diflunisal suggesting that its coordination to $\mathrm{Zn}$ (II) may result in pronounced antioxidant ability. In comparison with the reported Zn-NSAID analogues, ${ }^{27,28,36}$ the Zn-diflunisal complexes 1-5 are as active DPPH-, ABTS- and hydroxyl-scavengers and LOX-inhibitors with slight variations of the magnitude. Additionally, we may conclude that the present Zn-diflunisal complexes 1-5 may exhibit selective scavenging ability towards hydroxyl and ABTS radicals in contrast to DPPH radicals as also observed for previously Zn-NSAID complexes. Similar scavenging selectivity has been reported in the literature for many transition metal complexes showing selective scavenging activity against either DPPH radicals [82,83] or hydroxyl and ABTS radicals [27,28,32,36,39-46,84-86].

\subsection{Interaction of the complexes with serum albumins}

One of the most important roles of the albumins (SAs), which are the most abundant serum proteins, is the transportation of ions and drugs through the bloodstream towards their biological targets, i.e. cells and tissues [53]. Thus, the interaction of potential biologically active compounds (such as the reported complexes 1-5) with SAs is important to investigate as a first approach for the exploration of the potential biological activity, because the biological properties of the compounds may change when bound to albumins or novel alternative transportation pathways or mechanisms may arise [87].

Within this context, the interaction of complexes 1-5 with HSA and its homologue BSA was monitored by fluorescence emission spectroscopy. When the solutions of HSA and BSA are excited at $295 \mathrm{~nm}$, the fluorescence emission spectra present an intense emission band at $\lambda_{\mathrm{em}, \max }=352 \mathrm{~nm}$ and $343 \mathrm{~nm}$, respectively; this band is attributed to the presence of tryptophans, i.e. the tryptophan at position 214 in HSA and the tryptophans at positions 134 and 212 in BSA [53]. The addition of complexes 1-5 in the albumin solution resulted in a quenching of the SA fluorescence emission band with the simultaneously appearance of a second emission band at $416 \mathrm{~nm}$, which is characteristic for diflunisal compounds [12] followed by an isoemissive point at $374 \mathrm{~nm}$ or $381 \mathrm{~nm}$ in the fluorescence emission spectra of HSA or BSA, respectively (Fig. 5). The inner-filter effect [54] was calculated with eq. S1 and it was not so significant to affect the measurements. 

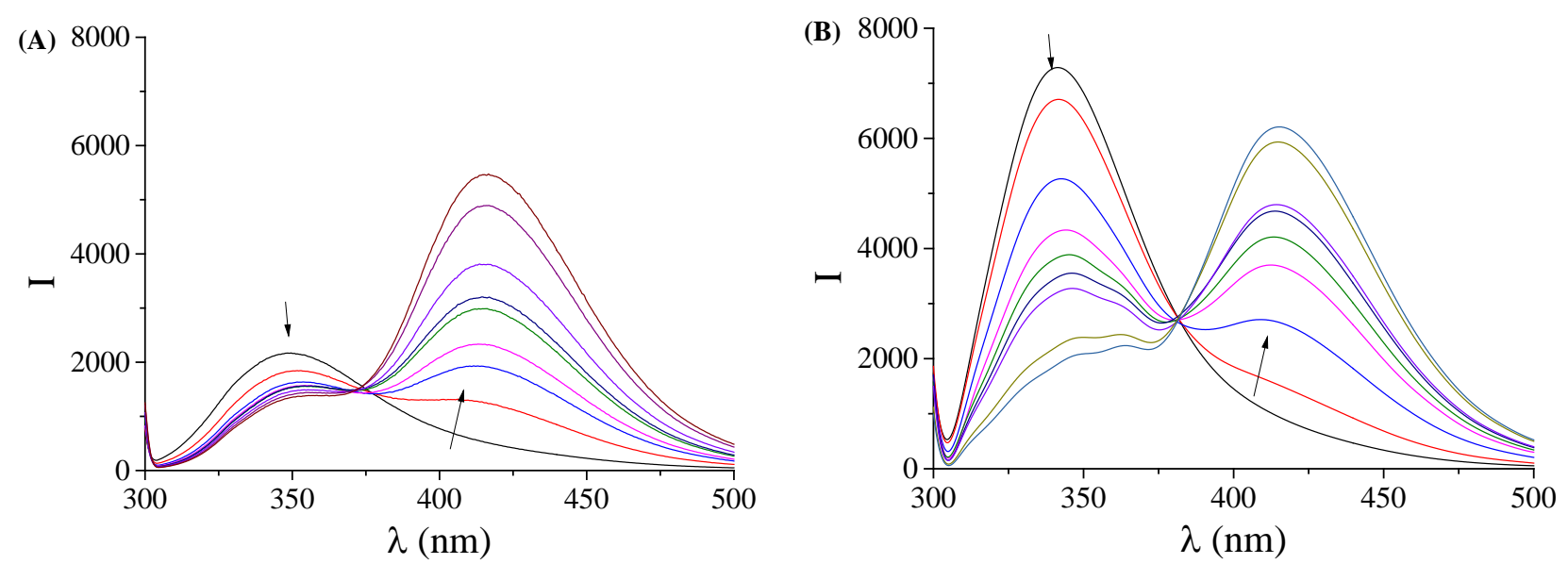

Fig. 5. Fluorescence emission spectra $\left(\lambda_{\text {exit }}=295 \mathrm{~nm}\right)$ for $(\mathrm{A}) \mathrm{HSA}([\mathrm{HSA}]=3 \mu \mathrm{M})$ in buffer solution in the absence and presence of increasing amounts of $1(r=[1] /[\mathrm{HSA}]=0-7.3)$ and (B) BSA $([\mathrm{BSA}]=3 \mu \mathrm{M})$ in buffer solution in the absence and presence of increasing amounts of $4(\mathrm{r}=$ $[4] /[\mathrm{BSA}]=0-7.3)$. The arrows show the changes of intensity upon increasing amounts of the complex.

The quenching in the fluorescence emission spectra of the SAs induced by the presence of the complexes was low-to-moderate in the case of HSA (the quenching of the initial HSA fluorescence emission ( $\Delta \mathrm{I} / \mathrm{Io}$ ) was up to $\sim 69 \%$ in the presence of complex 4, Fig. $6(\mathrm{~A})$ ) and more enhanced, i.e. moderate-to-significant for BSA (the quenching of the initial BSA fluorescence emission $(\Delta \mathrm{I} / \mathrm{Io})$ was up to $\sim 79 \%$ in the presence of complex 1, Fig. $6(\mathrm{~B}))$. The observed quenching may be attributed to possible changes in tryptophan environment of SA probably induced by changes in albumin secondary structure as a result of the binding of each complex to SA [88].
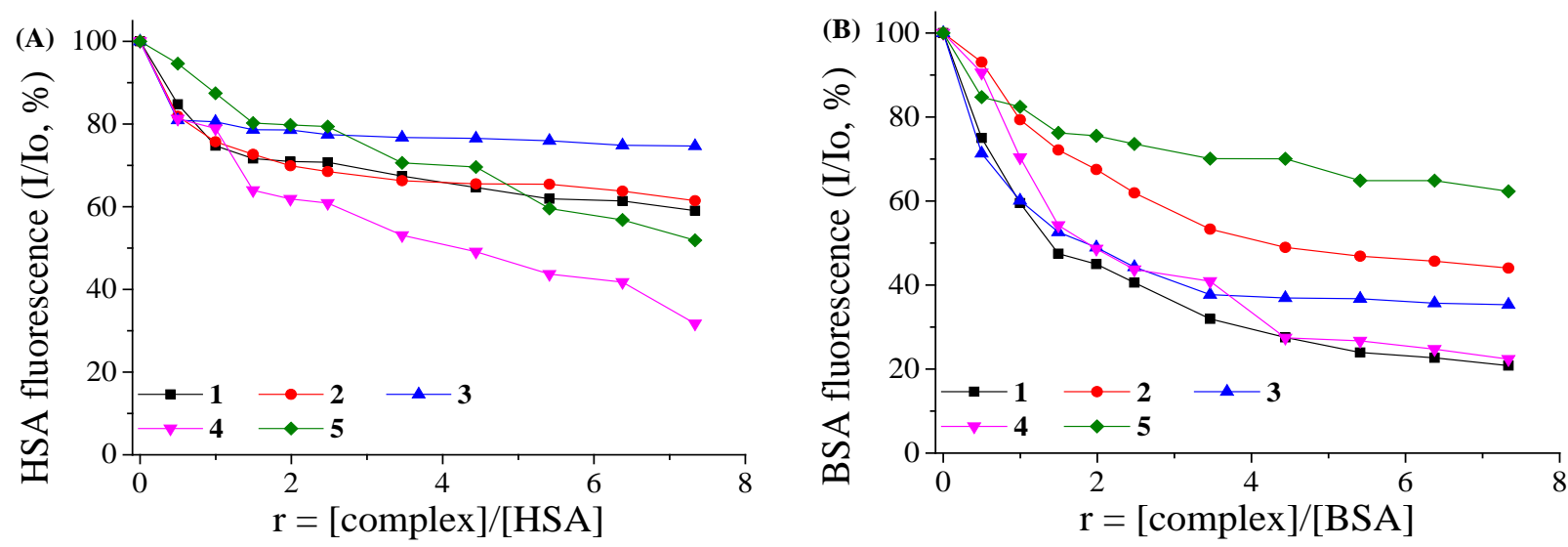

Fig. 6. (A) Plot of relative HSA fluorescence intensity at $\lambda_{\mathrm{em}}=352 \mathrm{~nm}(\mathrm{I} / \mathrm{Io}, \%)$ vs $r(r=$ [complex]/[HSA]) for complexes $\mathbf{1 - 5}$ (up to $59.1 \%$ of the initial HSA fluorescence for $\mathbf{1}, 61.5 \%$ for 2, $74.7 \%$ for 3, 31.8\% for 4 and 51.9\% for 5) in buffer solution (150 $\mathrm{mM} \mathrm{NaCl}$ and $15 \mathrm{mM}$ 
trisodium citrate at $\mathrm{pH}$ 7.0). (B) Plot of relative BSA fluorescence intensity at $\lambda_{\mathrm{em}}=343 \mathrm{~nm}(\mathrm{I} / \mathrm{Io}$, \%) vs $r$ ( $r=$ [complex]/[BSA]) for complexes 1-5 (up to 20.8\% of the initial BSA fluorescence for 1, $44.1 \%$ for 2 , $35.3 \%$ for $3,22.4 \%$ for 4 and $62.9 \%$ for 5 ) in buffer solution (150 mM NaCl and 15 $\mathrm{mM}$ trisodium citrate at $\mathrm{pH} 7.0)$.

The quenching constants $\left(\mathrm{k}_{\mathrm{q}}\right)$ concerning the interaction of the compounds with the SAs were calculated (Table 5) from the corresponding Stern-Volmer plots (Figs. S7 and S8) by the Stern-Volmer quenching equation (eqs. S2 and S3) and taking $\tau_{0}=10^{-8} \mathrm{~s}$ as fluorescence lifetime of tryptophan in SA [55]. The derived $\mathrm{k}_{\mathrm{q}}$ constants are significantly higher than $10^{10} \mathrm{M}^{-1} \mathrm{~s}^{-1}$ suggesting the existence of a static quenching mechanism [57]. The $\mathrm{k}_{\mathrm{q}}$ constants of complexes 1-5 may show a significant SA-quenching ability for the complexes and are higher than that of free Hdifl with complexes $\mathbf{4}$ and $\mathbf{2}$ showing the highest $\mathrm{k}_{\mathrm{q}}$ constants for HSA and BSA, respectively among the compounds. The $\mathrm{k}_{\mathrm{q}}$ constant s of complexes 1-5 are within the range found for a series of metalcomplexes bearing NSAIDs as ligands [12-14,26-28,35,36,39-46].

Table 5. The albumin constants and parameters for diflunisal and its complexes 1-5.

\begin{tabular}{|c|c|c|c|}
\hline Complexes & $k_{q}\left(M^{-1} s^{-1}\right)$ & $K\left(M^{-1}\right)$ & $\mathbf{n}$ \\
\hline \multicolumn{4}{|l|}{ HSA } \\
\hline Hdifl [12] & $2.67( \pm 0.16) \times 10^{12}$ & $1.22( \pm 0.07) \times 10^{5}$ & 0.53 \\
\hline$\left[\mathrm{Zn}(\mathrm{difl})_{2}(\mathrm{MeOH})_{4}\right], \mathbf{1}$ & $6.63( \pm 0.22) \times 10^{12}$ & $3.14( \pm 0.11) \times 10^{5}$ & 0.46 \\
\hline [Zn(difl) $)_{2}$ (bipyam)], 2 & $5.54( \pm 0.34) \times 10^{12}$ & $5.64( \pm 0.19) \times 10^{5}$ & 0.39 \\
\hline [Zn(difl) $)_{2}$ (bipy)], 3 & $5.34( \pm 0.33) \times 10^{11}$ & $9.94( \pm 0.35) \times 10^{5}$ & 0.26 \\
\hline [Zn(difl) $)_{2}($ phen $\left.)\right], 4$ & $7.52( \pm 0.20) \times 10^{12}$ & $2.45( \pm 0.18) \times 10^{5}$ & 0.69 \\
\hline$\left[\mathrm{Zn}(\mathrm{difl})_{2}(\mathrm{Hpko})_{2}\right], 5$ & $4.09( \pm 0.07) \times 10^{12}$ & $5.59( \pm 0.26) \times 10^{4}$ & 0.84 \\
\hline
\end{tabular}

\section{BSA}

\begin{tabular}{lccc}
\hline Hdifl [12] & $1.53( \pm 0.08) \times 10^{13}$ & $1.93( \pm 0.15) \times 10^{5}$ & 1.04 \\
[Zn(difl $\left.)_{2}(\mathrm{MeOH})_{4}\right], \mathbf{1}$ & $1.74( \pm 0.06) \times 10^{13}$ & $2.44( \pm 0.07) \times 10^{5}$ & 0.94
\end{tabular}




$\begin{array}{cccc}{\left[\text { Zn }(\text { difl })_{2}(\text { bipyam })\right], 2} & 7.61( \pm 0.29) \times 10^{13} & 1.19( \pm 0.05) \times 10^{5} & 0.79 \\ {\left[\text { Zn }(\text { difl })_{2}(\text { bipy })\right], 3} & 1.43( \pm 0.08) \times 10^{13} & 4.26( \pm 0.14) \times 10^{5} & 0.72 \\ {\left[\text { Zn }(\text { difl })_{2}(\text { phen })\right], 4} & 1.62( \pm 0.04) \times 10^{13} & 2.01( \pm 0.07) \times 10^{5} & 0.95 \\ {\left[\text { Zn }(\text { difl })_{2}(\text { Hpko })_{2}\right], 5} & 2.70( \pm 0.19) \times 10^{12} & 2.17( \pm 0.08) \times 10^{5} & 0.44\end{array}$

The SA-binding constants (K) of complexes 1-5 were determined (Table 5) from the corresponding Scatchard plots (Figs. S9 and S10) using the Scatchard equation (eq. S4). The K constants of all complexes 1-5 are relatively high and are similar with those calculated for a series of metal-NSAID complexes [12-14,26-28,35,36,39-46]. In average, the complexes exhibit for HSA higher affinity than free Hdifl and for BSA similar affinity with free Hdifl, with complex $\mathbf{3}$ bearing the highest $\mathrm{K}$ constants among the present compounds for both albumins.

The SA-binding constants of complexes 1-5 are lying in the range $5.59 \times 10^{4}-9.94 \times 10^{5} \mathrm{M}^{-1}$ (Table 5). These values may be considered are high enough to reveal the binding of the complexes to SAs in order to get transferred to the potential biotargets. On the other hand, the K constants are significantly lower than the binding constant of avidin with diverse compounds $\left(10^{15} \mathrm{M}^{-1}\right)$ [89] which is among the strongest known non-covalent reversible interactions [88]; such comparison may be an indication that the complexes are bound to the SAs not too tightly and can get released upon arrival to the desired target.

\subsection{Interaction of the complexes with CT DNA}

The interaction mode of metal complexes with double-stranded DNA is mainly dependent on the structure of the complexes and the nature of their ligands. The existence of labile ligands may lead to their replacement by a nitrogen atom of a DNA-base resulting thus in covalent binding of the metal to the DNA-bases. Complexes which remain stable in solution may either induce cleavage of the DNA double helix or show non-covalent interaction with DNA, i.e. intercalation inbetween DNA-bases via $\pi \rightarrow \pi$ stacking interaction of the complex planar aromatic rings and DNAbases, electrostatic interaction due to the development of Coulomb forces towards the DNAphosphate groups or groove-binding arising from the existence of hydrophobic or hydrogen bonding or van der Waals forces [90]. The interaction of complexes 1-5 with CT DNA was investigated in vitro by UV spectroscopy and viscosity measurements and indirectly via the evaluation of the EBdisplacing ability of the complexes examined by fluorescence emission spectroscopy. 
UV spectroscopy is usually used as a preliminary evaluation of the DNA-interaction of the complexes in order to obtain information in regard to the in vitro binding mode and strength of the complexes with CT DNA. The UV spectra of a CT DNA solution were recorded in the presence of complexes 1-5 at increasing amounts (for different $r$ values) and vice versa, i.e. the UV spectra of the complexes were recorded in the presence of CT DNA at increasing amounts. During such UV spectroscopic titration studies, the existence of any interaction may be revealed via the changes induced to the CT DNA-band at 258-260 nm or the intra-ligand transition bands of the complexes, thus, providing initial information of such interaction.

The UV spectra of a CT DNA solution in the presence of complex 2 at increasing $r$ values are shown representatively in Fig. 7(A). The band at $\lambda_{\max }=258 \mathrm{~nm}$ exhibits a hyperchromism accompanied by a red-shift up to $261 \mathrm{~nm}$, indicating thus the interaction with CT DNA which leads to the formation of a new complex-DNA conjugate [91] resulting in stabilization of the CT DNA double-helix [92]. Quite similar is the behavior of CT DNA in the presence of the other complexes.
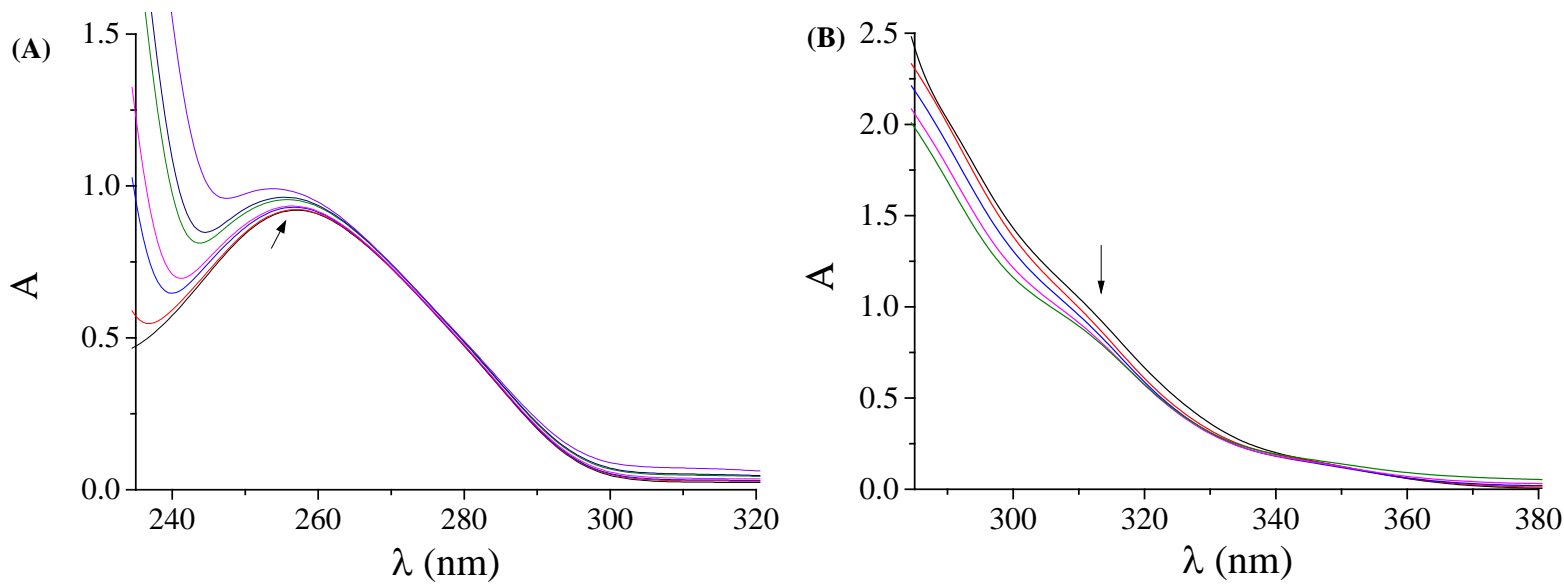

Fig. 7. (A) UV spectra of CT DNA (0.14 mM) in buffer solution (150 mM NaCl and $15 \mathrm{mM}$ trisodium citrate at $\mathrm{pH}$ 7.0) in the absence or presence of complex 2 . The arrows show the changes upon increasing amounts of the complex. (B) UV spectra of DMSO solution of complex $\mathbf{1}(50 \mu \mathrm{M})$ in the presence of increasing amounts of CT DNA ( $\mathrm{r}^{\prime}=[\mathrm{DNA}] /[$ compound $\left.]=0-0.8\right)$. The arrow shows the changes upon increasing amounts of CT DNA.

In the UV spectra of complex 1 (Fig. 7(B)), the intra-ligand band observed at 310(sh) nm exhibited in the presence of CT DNA a hypochromism of up to 15\%. Similar is the behavior of complexes 2-5 in the presence of DNA, which presented nevertheless a similar or lower hypochromism (Table 6). The observed hypochromism might be attributed to $\pi \rightarrow \pi$ stacking interaction between the aromatic chromophores (from difl $^{-}$and/or the $\mathrm{N}, \mathrm{N}^{\prime}$-donor ligands) of the complexes and DNA-base pairs [93]. Nevertheless, the percentage of hypochromism is low-to- 
moderate in most cases and safe conclusions in regard to the possible complex-DNA interaction mode only from the existing UV spectroscopic data cannot be derived; thus, viscosity measurements were carried in the attempt to better clarify the interaction mode.

Table 6. Spectral features of the interaction of complexes 1-5 with CT DNA. UV-band ( $\lambda$ in nm) (percentage of the observed hyper-/hypo-chromism ( $\left.\Delta \mathrm{A} / \mathrm{A}_{0}, \%\right)$, blue-/red-shift of the $\lambda_{\max }(\Delta \lambda$, $\mathrm{nm})$ ) and DNA-binding constants $\left(\mathrm{K}_{\mathrm{b}}\right)$.

\begin{tabular}{|c|c|c|}
\hline Complexes & $\operatorname{Band}\left(\Delta \mathrm{A} / \mathrm{A}_{0}{ }^{\mathrm{a}}, \Delta \lambda^{\mathrm{b}}\right)$ & $K_{b}\left(M^{-1}\right)$ \\
\hline Hdifl [12] & $295(\mathrm{sh})(+15.0,+2)$ & $3.08( \pm 0.15) \times 10^{3}$ \\
\hline$\left[\mathrm{Zn}(\operatorname{difl})_{2}(\mathrm{MeOH})_{4}\right], \mathbf{1}$ & $310(\mathrm{sh})(-15,+2)$ & $4.97( \pm 0.13) \times 10^{4}$ \\
\hline [Zn(difl) $)_{2}($ bipyam)], 2 & $319(-6.8,-3)$ & $3.72( \pm 0.16) \times 10^{4}$ \\
\hline$\left[\mathrm{Zn}(\mathrm{difl})_{2}(\mathrm{bipy})\right], \mathbf{3}$ & $312(-5.0,0)$ & $3.53( \pm 0.22) \times 10^{5}$ \\
\hline$\left[\mathrm{Zn}(\operatorname{difl})_{2}\right.$ (phen)], $\mathbf{4}$ & $318(-9.5,0)$ & $3.88( \pm 0.18) \times 10^{5}$ \\
\hline$\left[\mathrm{Zn}(\text { difl })_{2}(\mathrm{Hpko})_{2}\right], 5$ & $328(-12.0,0)$ & $5.85( \pm 0.11) \times 10^{5}$ \\
\hline a “+” denotes hyperch & m, “-” denotes & mism \\
\hline
\end{tabular}

The DNA-binding constants $\left(\mathrm{K}_{\mathrm{b}}\right)$ of complexes 1-5 (Table 6) were determined from the plots [DNA]/( $\left.\varepsilon_{\mathrm{A}}-\varepsilon_{\mathrm{f}}\right)$ versus [DNA] (Fig. S11) by the Wolfe-Shimer equation (eq. S5) [56]. In brief, the $\mathrm{K}_{\mathrm{b}}$ constants of the complexes 1-5 are significantly higher than that of free Hdifl showing that its coordination to Zn results in enhanced DNA-binding affinity. The $\mathrm{K}_{\mathrm{b}}$ constants of most of the complexes 1-5 are higher than that of the classical intercalator EB $\left(=1.23( \pm 0.07) \times 10^{5} \mathrm{M}^{-1}\right)$ as previously calculated by Kessissoglou and co-workers [94], with complex 5 bearing the highest $\mathrm{K}_{\mathrm{b}}$ constant among the complexes. In average, the $\mathrm{K}_{\mathrm{b}}$ constants of the $\mathrm{Zn}$-diflunisal complexes 1-5 are of the same magnitude with those of their $\mathrm{Cu}(\mathrm{II})$-diflunisal analogues [12] and other Zn-NSAID complexes $[27,28,36]$ and in the range found for a series of previously reported metal-NSAID complexes [12-14,39-46].

The interaction of complexes 1-5 with CT DNA was also studied by monitoring the changes of viscosity of a DNA solution upon addition of complexes 1-5. The relative DNA-viscosity $\left(\eta / \eta_{0}\right)$ 
is sensitive to the relative DNA-length changes $\left(\mathrm{L} / \mathrm{L}_{0}\right)$ occurring in the presence a DNA-binder since they are correlated by the equation $L / L_{0}=\left(\eta / \eta_{0}\right)^{1 / 3}[95]$. The DNA-viscosity will show an increase in the case of intercalation and will decrease slightly or remain unchanged in the case of non-classical intercalation, i.e. groove-binding or electrostatic interaction. Within this context, the viscosity of a CT DNA solution $(0.1 \mathrm{mM})$ was monitored in the presence of increasing amounts of complexes 1-5 (up to the value of $r=0.35$ ) and showing a considerable increase upon addition of the complexes (Fig. 8). This behavior may reveal the existence of intercalation between DNA and the complexes which may take place via the insertion of the complexes in-between the DNA-bases; this intercalation will induce increase of the separation distance of the DNA bases in order to accommodate the intercalating compounds leading subsequently to an increase of DNA-viscosity [39-46,95]. The existing conclusion of intercalation may clarify the behavior shown during the UV spectroscopic studies.

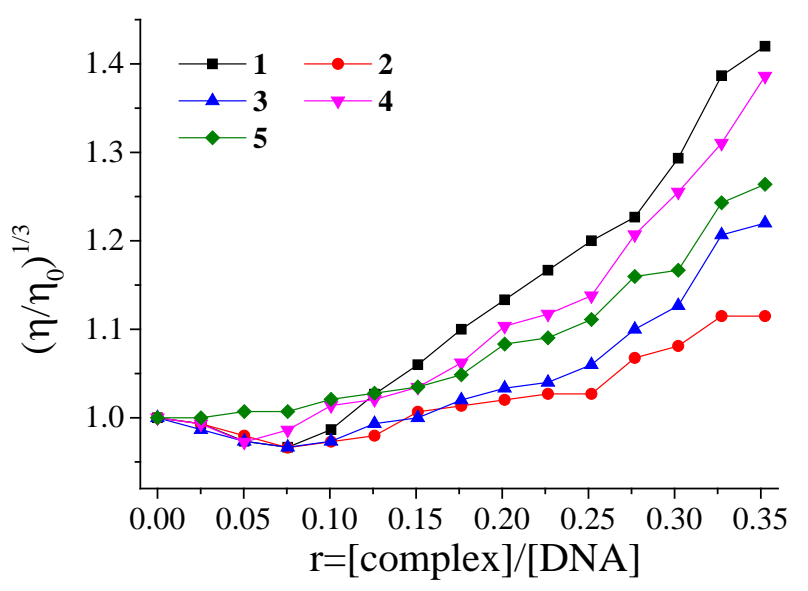

Fig. 8. Relative viscosity $\left(\eta / \eta_{\mathrm{o}}\right)^{1 / 3}$ of CT DNA $(0.1 \mathrm{mM})$ in buffer solution (150 mM NaCl and 15 $\mathrm{mM}$ trisodium citrate at $\mathrm{pH}$ 7.0) in the presence of complexes 1-5 at increasing amounts $(r=$ [complex]/[DNA]).

EB is a typical DNA-intercalation indicator and its replacement by a potential DNAintercalator may verify the intercalating ability of the complexes. The intercalation of EB to DNA takes place via the insertion of the EB-phenanthridine ring in-between DNA bases. Evidence of this intercalation is the appearance of an intense fluorescence emission band at $592 \mathrm{~nm}$ in the fluorescence emission spectra of a solution containing this EB-DNA conjugate, when the solution is excited at $540 \mathrm{~nm}$; this band may be quenched upon addition of another DNA-intercalator [53,96].

Within this context, the fluorescence emission spectra $\left(\lambda_{\text {exc }}=540 \mathrm{~nm}\right)$ of the EB-DNA conjugate which was obtained after pre-treatment of $\mathrm{EB}([\mathrm{EB}]=20 \mu \mathrm{M})$ with DNA ([DNA] $=26$ 
$\mu \mathrm{M}$ ) were recorded in the presence of increasing amounts of complexes 1-5 up to the value of $\mathrm{r}=$ 0.27 (representatively shown for $\mathbf{2}$ in Fig. 9(A)). The addition of the complexes into the EB-DNA solution may induce a moderate-to-significant quenching (Fig. 9(B)) of the EB-DNA emission band at $592 \mathrm{~nm}$ (the final quenching $(\Delta \mathrm{I} / \mathrm{Io})$ is up to $77.3 \%$ of the initial EB-DNA fluorescence, Table 7$)$. Such behavior may reveal the ability of the complexes to displace EB from DNA-intercalation sites and may indicate indirectly the existence of intercalation of the complexes to CT DNA [57].
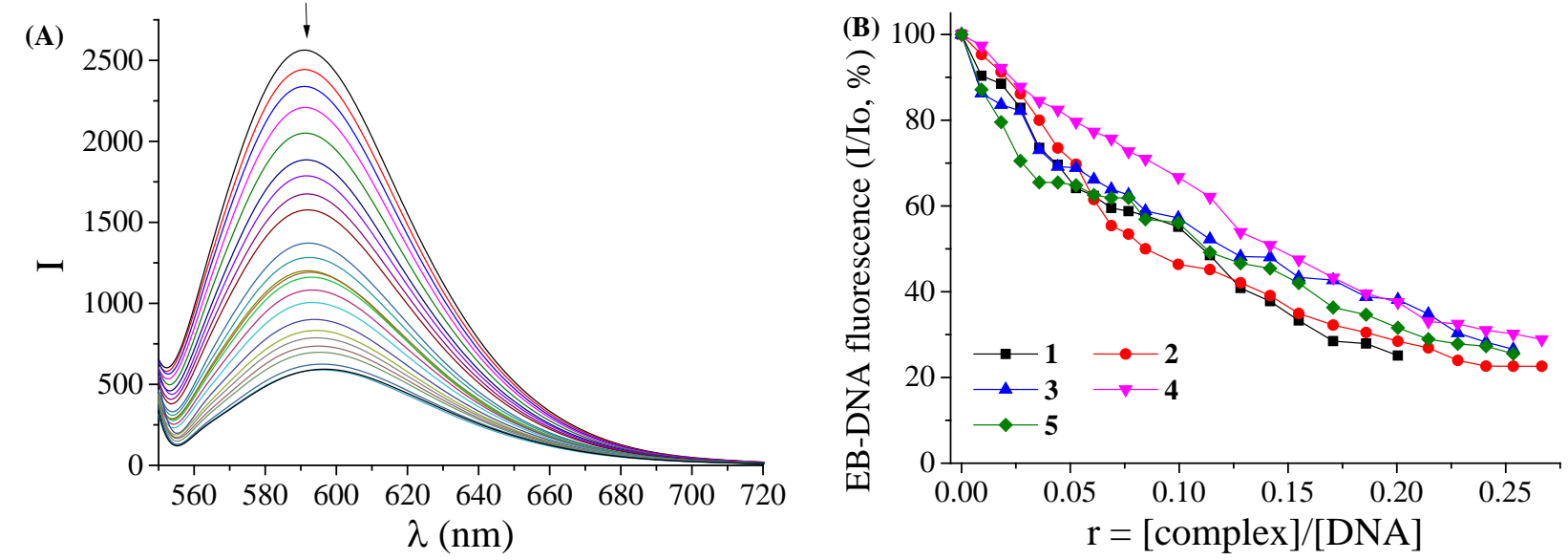

Fig. 9. (A) Fluorescence emission spectra $\left(\lambda_{\text {exc }}=540 \mathrm{~nm}\right)$ for EB-DNA ([EB] $=20 \mu \mathrm{M}$, [DNA] $=26$ $\mu \mathrm{M}$ ) in buffer solution in the absence and presence of increasing amounts of complex 2 (up to the value of $r=0.27$ ). The arrow shows the changes of intensity upon increasing amounts of 2 . (B) Plot of EB-DNA relative fluorescence intensity $(\% \mathrm{I} / \mathrm{Io})$ at $\lambda_{\mathrm{em}}=592 \mathrm{~nm}$ vs $r(r=$ [complex]/[DNA]) in buffer solution (150 mM NaCl and $15 \mathrm{mM}$ trisodium citrate at $\mathrm{pH}$ 7.0) in the presence of complexes 1-5 (quenching up to 25.1\% of the initial EB-DNA fluorescence for 1, 22.7\% for 2, 26.6\% for 3, $28.9 \%$ for $\mathbf{4}$ and $25.6 \%$ for $\mathbf{5}$ ).

Table 7. Percentage of EB-DNA fluorescence quenching ( $\Delta \mathrm{I} / \mathrm{Io}, \%)$, Stern-Volmer constants (Ksv) and quenching constants of the EB-DNA fluorescence $\left(\mathrm{k}_{\mathrm{q}}\right)$ for complexes 1-5.

\begin{tabular}{|c|c|c|c|}
\hline Complexes & $\Delta \mathrm{I} / \mathbf{I} 0(\%)$ & $\operatorname{Ksv}\left(M^{-1}\right)$ & $\mathbf{k q}\left(\mathbf{M}^{-1} \mathbf{s}^{-1}\right)$ \\
\hline Hdifl [12] & 65.0 & $8.59( \pm 0.35) \times 10^{5}$ & $3.73( \pm 0.15) \times 10^{13}$ \\
\hline$\left[\mathrm{Zn}(\operatorname{difl})_{2}(\mathrm{MeOH})_{4}\right], \mathbf{1}$ & 74.9 & $1.08( \pm 0.03) \times 10^{5}$ & $4.69( \pm 0.11) \times 10^{12}$ \\
\hline [Zn(difl)2(bipyam)], 2 & 77.3 & $5.16( \pm 0.14) \times 10^{5}$ & $2.24( \pm 0.06) \times 10^{13}$ \\
\hline [Zn(difl) $)_{2}($ bipy)], 3 & 73.4 & $1.50( \pm 0.04) \times 10^{5}$ & $6.53( \pm 0.15) \times 10^{12}$ \\
\hline
\end{tabular}



[Zn(difl) 2 (phen)], 4
71.1
$6.98( \pm 0.23) \times 10^{4}$
$3.04( \pm 0.10) \times 10^{12}$
[Zn(difl $\left.)_{2}(\text { Hpko })_{2}\right], 5$
74.5
$2.10( \pm 0.05) \times 10^{5}$
$9.12( \pm 0.20) \times 10^{12}$

The observed quenching of the EB-DNA fluorescence is in good agreement with the linear Stern-Volmer equation (eq. S2) [57] as shown in the corresponding Stern-Volmer plots ( $\mathrm{R}=0.99$, Fig. S12). The $\mathrm{K}_{\mathrm{Sv}}$ constants of the complexes (Table 7) are moderate-to-high verifying being in the range reported for other metal-NSAIDs complexes [39-46], with complex 2 bearing the highest Ksv constant among the Zn-diflunisal complexes. According to the literature the fluorescence lifetime of EB-DNA system has the value $\tau_{0}=23$ ns [58], and the quenching constants of the compounds in regard to their competition with EB were calculated with eq. S3. The $\mathrm{k}_{\mathrm{q}}$ constants (Table 7) are significantly higher than $10^{10} \mathrm{M}^{-1} \mathrm{~s}^{-1}$ suggesting, thus, that the quenching of the EB-DNA fluorescence from the complexes takes place via a static mechanism [57].

\subsection{Binding site identification - Docking calculations}

We identified two possible binding sites for HSA and BSA as shown in Figs. S13 and S14. The Dscore indicated that both are highly druggable, thus, establishing them as ideal drug targets.

The docking score (Table 8) obtained from our calculations indicates that complexes 1-5 bind stronger to HSA that free Hdifl and they rank starting from the highest binding affinity as $\mathbf{3}>\mathbf{5}$ $>\mathbf{2}>\mathbf{1}>\mathbf{4}>$ Hdifl. It should be noted that complexes 1-4 and free Hdifl prefer to bind to binding site 1 with the exception of 5 which binds in binding site 2 (Figs. 10 and S15). Complex 3 not only achieves a higher binding affinity but also increases the druggability score of the pocket from 1.18 to 1.21. It has non-bonded interactions with residues Asp451/ Lys199/ Trp214/ Arg218 as shown in Figs. 11 and S16. It seems that side-chain hydrogen bonding with Arg218 and Pi-Pi stacking interactions with Trp214 are important for binding as was also suggested in previous works [97-99].

On the other hand, complex 5 binding to site 2 increases the druggability from 1.16 to 1.25 and interacts with Leu491/Arg410/Tyr411/Phe403 (Fig. S17). There are many studies describing the interactions of NSAID drugs in particular, with Arg410 and Tyr411 [97,100]. Both sites are considered to be suitable; however, in terms of size and polarity, they are clearly different thus accounting for different specificities. 
Table 8. Binding affinities (in kcal/mol) and druggability score (Dscore) for diflunisal and its complexes 1-5.

\begin{tabular}{|c|c|c|}
\hline Complexes & Docking score (kcal/mol) & Dscore \\
\hline \multicolumn{3}{|l|}{ HSA } \\
\hline Hdifl & -7.40 & 1.18 \\
\hline$\left[\mathrm{Zn}(\operatorname{difl})_{2}(\mathrm{MeOH})_{4}\right], \mathbf{1}$ & -9.29 & 1.16 \\
\hline$\left[\mathrm{Zn}(\text { difl })_{2}(\right.$ bipyam)], 2 & -9.40 & 1.16 \\
\hline [Zn(difl) $)_{2}($ bipy)], 3 & -10.17 & 1.21 \\
\hline$\left[\mathrm{Zn}(\operatorname{difl})_{2}(\right.$ phen $\left.)\right], \mathbf{4}$ & -8.88 & 1.07 \\
\hline$\left[\mathrm{Zn}(\mathrm{difl})_{2}(\mathrm{Hpko})_{2}\right], 5$ & -9.96 & 1.25 \\
\hline \multicolumn{3}{|l|}{ BSA } \\
\hline Hdifl & -7.01 & 1.13 \\
\hline$\left[\mathrm{Zn}(\operatorname{difl})_{2}(\mathrm{MeOH})_{4}\right], \mathbf{1}$ & -7.47 & 1.14 \\
\hline [Zn(difl) $)_{2}($ bipyam)], 2 & -4.61 & 1.14 \\
\hline [Zn(difl) $)_{2}$ (bipy)], 3 & -8.98 & 1.19 \\
\hline$\left[\mathrm{Zn}(\text { difl })_{2}\right.$ (phen)], 4 & -4.19 & 1.13 \\
\hline$\left[\mathrm{Zn}(\text { difl })_{2}(\mathrm{Hpko})_{2}\right], 5$ & -4.34 & 1.13 \\
\hline
\end{tabular}

\section{CT DNA}

\begin{tabular}{|c|c|c|}
\hline Hdifl & -4.78 & 0.90 \\
\hline$\left[\mathrm{Zn}(\operatorname{difl})_{2}(\mathrm{MeOH})_{4}\right], \mathbf{1}$ & -2.11 & 0.95 \\
\hline [Zn(difl) $)_{2}$ (bipyam)], 2 & -4.91 & 1.00 \\
\hline [Zn(difl) $)_{2}$ (bipy)], 3 & -6.46 & 0.98 \\
\hline [Zn(difl) $)_{2}($ phen)], 4 & -3.23 & 1.03 \\
\hline$\left[\mathrm{Zn}(\text { difl })_{2}(\mathrm{Hpko})_{2}\right], 5$ & -6.85 & 0.87 \\
\hline
\end{tabular}




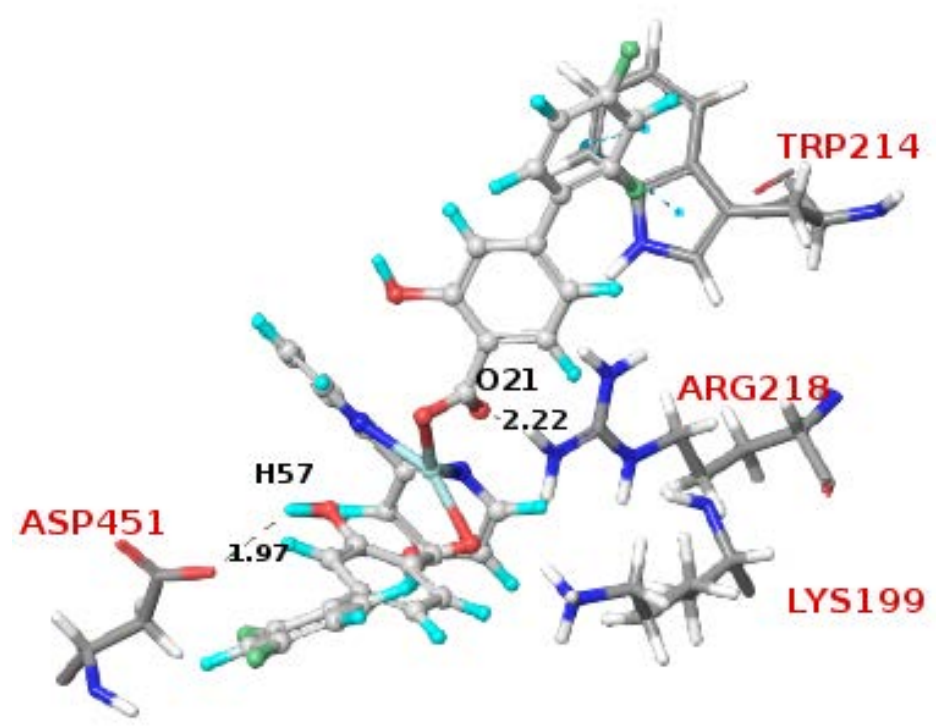

Fig. 10: Interactions of $\left[\mathrm{Zn}(\operatorname{difl})_{2}(\right.$ bipy) $], 3$ in the binding site of HSA.

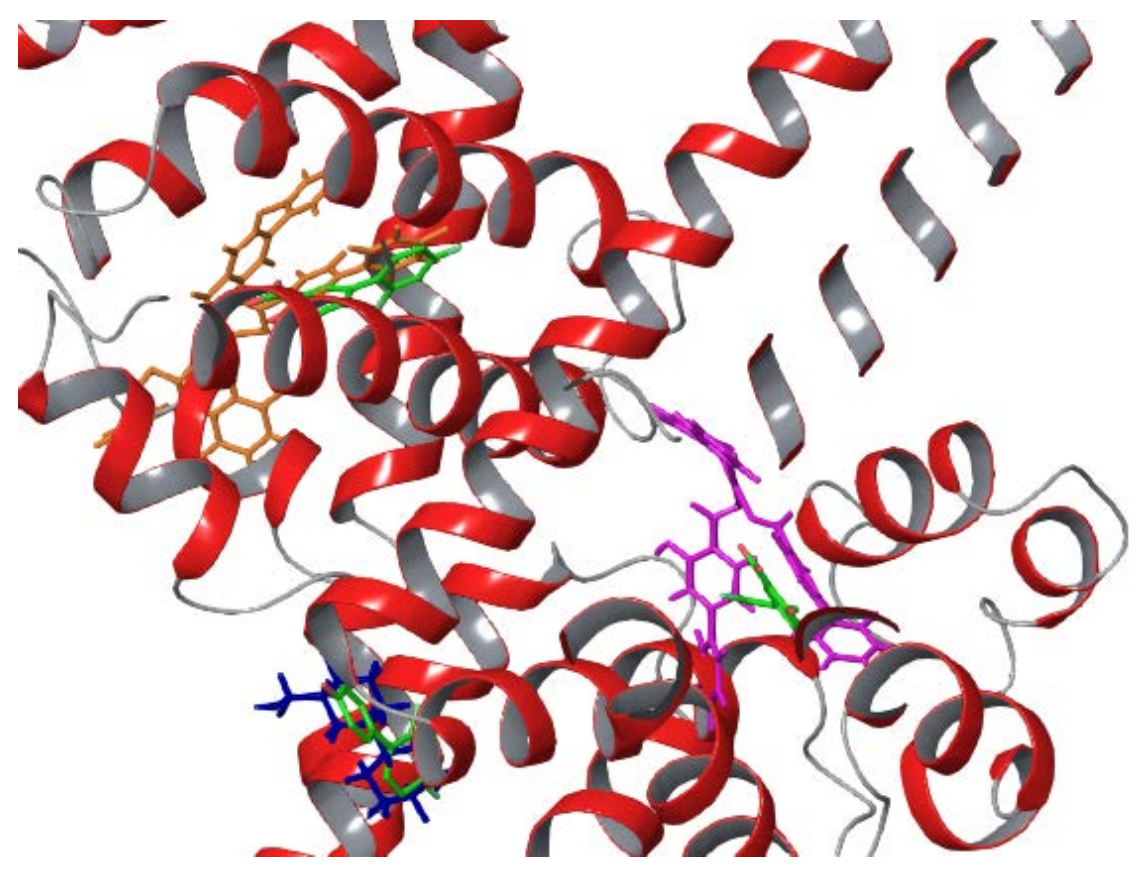

Fig. 11: Superimposition of docking structures of [Zn(difl $\left.)_{2}(\text { bipy)] in magenta, [Zn(difl })_{2}(\text { Hpko })_{2}\right]$ in orange and Hdifl in blue with diflunisal (reference structure 2BXE) in green, inside HSA.

In Fig. 11, we have depicted the results of our docking calculation with complexes $\mathbf{3}$ and $\mathbf{5}$ and free Hdifl with the structure of HSA with Hdifl from previous studies [97]. It is clear that complexes $\mathbf{3}$ and $\mathbf{5}$ bind almost at the same site and the position of our "control” diflunisal reproduces the previous result with extreme accuracy. Complex 3 gave also the best result for BSA and along with 1 bind stronger than free Hdifl. The ranking according to docking score (the lower the score, the highest the affinity) is: $\mathbf{3}>\mathbf{1}>$ Hdifl $>\mathbf{2} \sim \mathbf{5}>\mathbf{4}$. All complexes bind at binding site 2 
for BSA (Fig. S18), however, only complex 3 was found to improve the Dscore of the targeted site. Complex 3 presents the most interactions within the binding site as shown in the interaction diagram (Fig. S19), having non-bonded interactions with Arg409, Lys413 and Leu490. Our prediction is in agreement with previous results [101,102] that point out the significance of the interactions with Lys413 and Arg409. Overlaying the docking structures of our calculations, including complex $\mathbf{3}$ and our "control” free Hdifl with the crystal structure having naproxen bound [103], we see that they share a nearly identical position (Fig. 12).

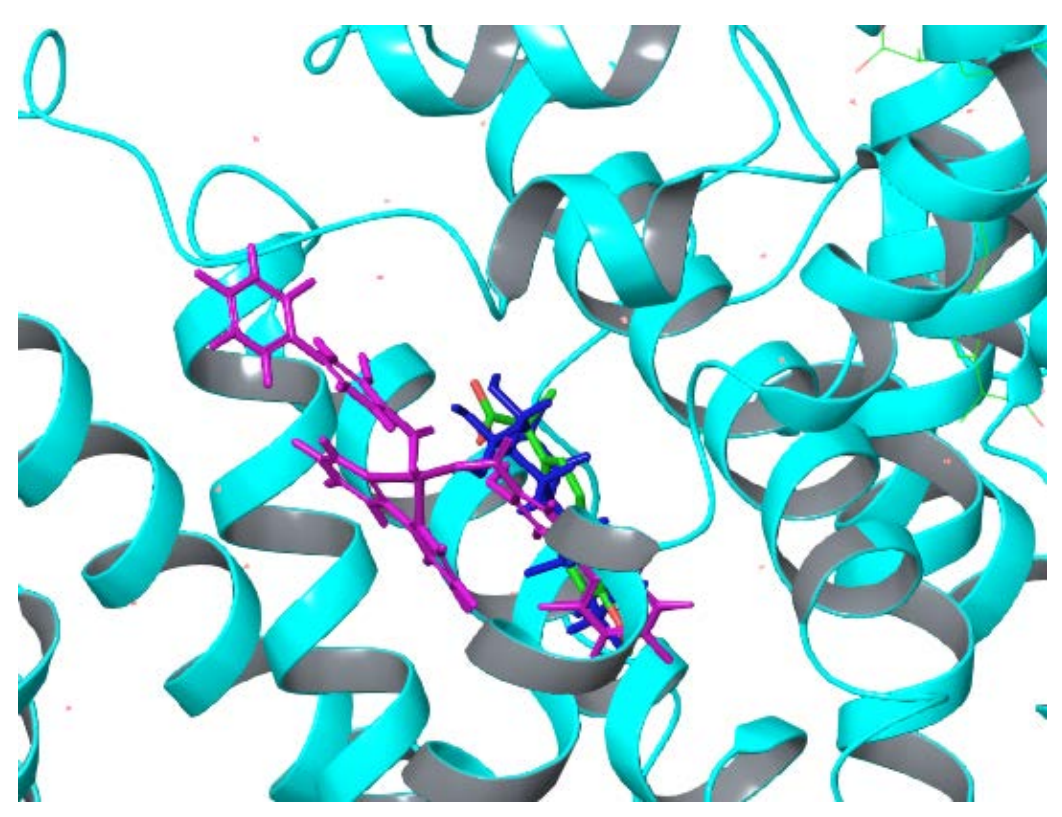

Fig. 12: Superimposition of docking structures of [Zn(difl) $)_{2}($ bipy)] in magenta, and Hdifl in blue with naproxen (reference structure 4OR0) in green, inside BSA.

Docking calculations with the CT DNA binding site (Fig. S20) indicate that the complex with the highest affinity is $\mathbf{5}$. In Fig. 13, the differences in binding position for complex $\mathbf{5}$ and free hdifl are presented and, therefore, they interact with different bases (Figs. S21 and S22). Complex 5 is hydrogen bonded with the side chains of Adenine 9 and Thymine 7, 19, having also Pi-Pi interactions with Guanine 16, 4 and Thymine 8. This justifies the interaction mode revealed from our experiments, that could be either intercalation (Pi-Pi interactions in-between the bases) or groove-binding via hydrogen bonding. Hdifl prefers Cytosine 11 and Guanine 16, 10, presenting only hydrogen bonding interactions. All complexes with the exception of $\mathbf{1}$ and $\mathbf{4}$ seem to bind tighter than free Hdifl but in different sites (Fig. S23). However, complexes $\mathbf{1}$ and $\mathbf{4}$ are the ones binding closer to the position of Hdifl. 


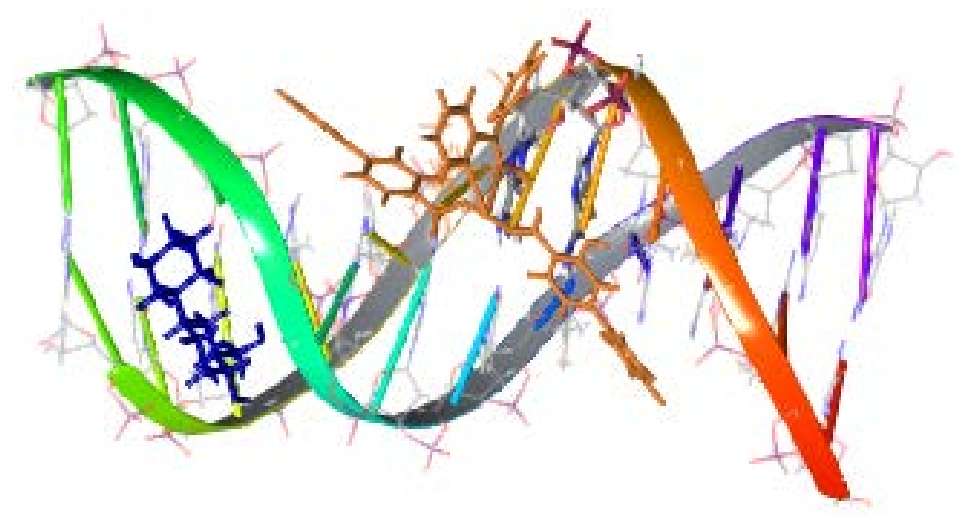

Fig. 13: Docking structures of $\left[\mathrm{Zn}(\operatorname{difl})_{2}(\mathrm{Hpko})_{2}\right]$ in orange and Hdifl in blue interacting with CT DNA.

\section{Conclusions}

We synthesized and characterized five novel mononuclear zinc(II) complexes with the NSAID diflunisal. The crystal structures of three complexes, namely [Zn(difl-O)(difl$\left.\mathrm{O}, \mathrm{O}^{\prime}\right)\left(\right.$ bipyam)] $\cdot \mathrm{MeOH}, \mathbf{2} \cdot \mathrm{MeOH},\left[\mathrm{Zn}(\text { difl-O,O') })_{2}(\text { bipy)], } 3 \text { and [Zn(difl-O) })_{2}(\text { Hpko-N,N') })_{2}\right.$ ], 5 were determined by X-ray crystallography. In all complexes, the deprotonated diflunisal ligands are bound to octahedral zinc(II) in a bidentate mode in complexes $\mathbf{2 - 4}$, or in monodentate mode in complexes 1 and 5.

The biological activity of the complexes was evaluated in vitro in regard to their ability to scavenge DPPH, ABTS and hydroxyl radicals and to inhibit soybean lipoxygenase activity and also to bind to serum albumins and CT DNA. In general, the complexes were more active radical scavengers and LOX inhibitors than free diflunisal. The interaction of the complexes with albumins showed their potential ability to bind to the albumins in order to get transferred to their potential biological targets where they may be released. Intercalation is the most possible interaction mode of the complexes with CT DNA as revealed by DNA-viscosity experiments, and EB-displacement ability of the complexes suggest that they are better "DNA-binders" than free diflunisal.

Molecular docking simulations revealed that all complexes bind to serum albumins and CT DNA within the predicted binding sites, while most of them interact in a stronger manner with the proteins than the NSAID drug. Complex [Zn(difl)2(bipy)], 3 was found to be the strongest binder for both albumins whereas $\left[\mathrm{Zn}(\mathrm{difl})_{2}(\mathrm{Hpko})_{2}\right], \mathbf{5}$ was the one to bind the strongest in CT DNA .

Computational results are in good agreement with the experimental data as far as binding activity is concerned and suggest that all five Zn-diflunisal complexes are potent SA- and DNA- 
binders and, thus, can be used as drugs. Results regarding the in vitro antioxidant activity of the complexes are also promising, enhancing our claim for their possible application as metallodrugs.

\section{Supplementary}

CCDC 1511461-1511463 contain the supplementary crystallographic data for this paper. These data can be obtained free of charge via www.ccdc.cam.ac.uk/conts/retrieving.html (or from the Cambridge Crystallographic Data Centre, 12 Union Road, Cambridge CB21EZ, UK; fax: (+44) 1223-336-033; or deposit@ccde.cam.ac.uk). 


\section{References}

[1] C.P. Duffy, C.J. Elliott, R.A. O’Connor, M.M. Heenan, S. Coyle, I.M. Cleary, K. Kavanagh, S. Verhaegen, C.M. O’Loughlin, R. NicAmhlaoibh, M. Clynes, Eur. J. Cancer 34 (1998) 12501259.

[2] A.R. Amin, P. Vyas, M. Attur, J. Leszczynskapiziak, I.R. Patel, G. Weissmann, S.B. Abramson, Proc. Natl. Acad. Sci. 92 (1995) 7926-7930.

[3] K. Kim, J. Yoon, J.K. Kim, S.J. Baek, T.E. Eling, W.J. Lee, J. Ryu, J.G. Lee, J. Lee, J. Yoo, Biochem. Biophys. Res. Commun. 325 (2004) 1298-1303.

[4] D.H. Woo, I. Han, G. Jung, Life Sci. 75 (2004) 2439-2449.

[5] M.L. Smith, G. Hawcroft, M.A. Hull, Eur. J. Cancer 36 (2000) 664-674.

[6] A. Inoue, S. Muranaka, H. Fujita, T. Kanno, H. Tamai, K. Utsumi, Free Radical Biol. Med. 37 (2004) 1290-1299.

[7] T. Zhang, T. Otevrel, Z.Q. Gao, Z.P. Gao, S.M. Ehrlich, J.Z. Fields, B.M. Boman, Cancer Res. 61 (2001) 8664-8667.

[8] J.E. Weder, C.T. Dillon, T.W. Hambley, B.J. Kennedy, P.A. Lay, J.R. Biffin, H.L. Regtop, N.M. Davies, Coord. Chem. Rev. 232 (2002), 95-126.

[9] S. S. Adams, InflammoPharmacology 7 (1999) 191-197.

[10] R.N. Brogden, R.C. Heel, G.E. Pakes, T.M. Speight, G.S. Avery, Drugs 19 (1980) 84-106.

[11] M.G.M. Lawton, P.J. Chapman, Australian Dental Journal 38 (1993) 265-271.

[12] S. Fountoulaki, F. Perdih, I. Turel, D.P. Kessissoglou, G. Psomas, J. Inorg. Biochem. 105 (2011) 1645-1655.

[13] S. Tsiliou, L.-A. Kefala, A.G. Hatzidimitriou, D.P. Kessissoglou, F. Perdih, A.N. Papadopoulos, I. Turel, G. Psomas, J. Inorg. Biochem. 160 (2016) 125-139.

[14] S. Perontsis, A.G. Hatzidimitriou, A.N. Papadopoulos, G. Psomas, J. Inorg. Biochem. 162 (2016) 9-21.

[15] H. Tapiero, K.D. Tew, Biomed. Pharmacother. 57 (2003) 399-411.

[16] G.K. Walkup, S.C. Burdette, S.J. Lippard, R.Y. Tsien, J. Am. Chem. Soc. 122 (2000) 56445645. 
[17] B.L. Vallee, D.S. Auld, Biochemistry 32 (1993) 6493-6500.

[18] E.C. Fusch, B. Lippert, J. Am. Chem. Soc. 116 (1994) 7204-7209.

[19] C.P. Larson, U.R. Saha, H. Nazrul, PLoS Medicine 6 (2009) e1000175.

[20] J. d'Angelo, G. Morgant, N.E. Ghermani, D. Desmaele, B. Fraisse, F. Bonhomme, E. Dichi, M. Sghaier, Y. Li, Y. Journaux, J.R.J. Sorenson, Polyhedron 27 (2008) 537-546.

[21] H. Sakurai, Y. Kojima, Y. Yoshikawa, K. Kawabe, H. Yasui, Coord. Chem. Rev. 226 (2002) 187-198.

[22] Q. Zhou, T.W. Hambley, B.J. Kennedy, P.A. Lay, P. Turner, B. Warwick, J.R. Biffin, H.L. Regtop, Inorg. Chem. 39 (2000) 3742-3748.

[23] N.C. Kasuga, K. Sekino, M. Ishikawa, A. Honda, M. Yokoyama, S. Nakano, N. Shimada, C. Koumo, K. Nomiya, J. Inorg. Biochem. 96 (2003) 298-310.

[24] M.P. Lopez-Gresa, R. Ortiz, L. Perello, J. Latorre, M. Liu-Gonzalez, S. Garcia-Granda, M. Perez-Priede, E. Canton, J. Inorg. Biochem. 92 (2002) 65-74.

[25] D. Xiao, E. Wang, H. An, Z. Su, Y. Li, L. Gao, C. Sun, L. Xu, Chem.-Eur. J. 11 (2005) 6673-6686.

[26] A. Tarushi, K. Lafazanis, J. Klun, I. Turel, A.A. Pantazaki, G. Psomas, D.P. Kessissoglou, J. Inorg. Biochem. 121 (2013) 53-65.

[27] A. Tarushi, Z. Karaflou, J. Kljun, I. Turel, G. Psomas, A.N. Papadopoulos, D.P. Kessissoglou, J. Inorg. Biochem. 128 (2013) 85-96.

[28] A. Tarushi, X. Totta, A. Papadopoulos, J. Kljun, I. Turel, D.P. Kessissoglou, G. Psomas, Eur. J. Med. Chem. 74 (2014) 187-198.

[29] J.S. Casas, E.E. Castellano, M.D. Couce, J. Ellena, A. Sanchez, J. Sordo, C. Taboada, J. Inorg. Biochem. 100 (2006) 124-132.

[30] Z. Travnicek, V. Krystof, M. Sipl, J. Inorg. Biochem. 100 (2006) 214-225.

[31] M. Di Vaira, C. Bazzicalupi, P. Orioli, L. Messori, B. Bruni, P. Zatta, Inorg. Chem. 43 (2004) 3795-3797.

[32] G. Psomas, D.P. Kessissoglou, Dalton Trans. 42 (2013) 6252-6276.

[33] P. Lemoine, B. Viossat, N.H. Dung, A. Tomas, G. Morgant, F.T. Greenaway, J.R.J. Sorenson, J. Inorg. Biochem. 98 (2004) 1734-1749. 
[34] H. Abu Ali, B. Jabali, Polyhedron 107 (2016) 97-106

[35] A. Tarushi, F. Kastanias, V. Psycharis, C.P. Raptopoulou, G. Psomas, D.P. Kessissoglou, Inorg. Chem. 51 (2012) 7460-7462.

[36] A. Tarushi, P. Kastanias, C.P. Raptopoulou, V. Psycharis, D.P. Kessissoglou, A.N. Papadopoulos, G. Psomas, J. Inorg. Biochem. 163 (2016) 332-345.

[37] H. Abu Ali, S.N. Omar, M.D. Darawsheh, H. Fares, J. Coord. Chem., 2016, 69, 1110-1122

[38] A. Tarushi, X. Totta, C. Raptopoulou, V. Psycharis, G. Psomas, D.P. Kessissoglou, Dalton Trans. 41 (2012) 7082-7091.

[39] M. Zampakou, A.G. Hatzidimitriou, A.N. Papadopoulos, G. Psomas, J. Coord. Chem. 68 (2015) 4355-4372.

[40] M. Zampakou, V. Tangoulis, C.P. Raptopoulou, V. Psycharis, A.N. Papadopoulos, G. Psomas, Eur. J. Inorg. Chem. (2015) 2285-2294.

[41] A. Tarushi, S. Perontsis, A.G. Hatzidimitriou, A.N. Papadopoulos, D.P. Kessissoglou, G. Psomas, J. Inorg. Biochem. 149 (2015) 68-79.

[42] X. Totta, A.A. Papadopoulou, A.G. Hatzidimitriou, A. Papadopoulos, G. Psomas, J. Inorg. Biochem. 145 (2015) 79-93.

[43] A. Tarushi, C.P. Raptopoulou, V. Psycharis, D.P. Kessissoglou, A.N. Papadopoulos, G. Psomas, J Inorg Biochem. 140 (2014) 185-198.

[44] M. Zampakou, N. Rizeq, V. Tangoulis, A.N. Papadopoulos, F. Perdih, I. Turel, G. Psomas, Inorg. Chem. 53 (2014) 2040-2052.

[45] F. Dimiza, S. Fountoulaki, A.N. Papadopoulos, C.A. Kontogiorgis, V. Tangoulis, C.P. Raptopoulou, V. Psycharis, A. Terzis, D.P. Kessissoglou, G. Psomas, Dalton Trans. 40 (2011) 8555-8568.

[46] F. Dimiza, A.N. Papadopoulos, V. Tangoulis, V. Psycharis, C.P. Raptopoulou, D.P. Kessissoglou, G. Psomas, Dalton Trans. 39 (2010) 4517-4528.

[47] J. Marmur, J. Mol. Biol. 3 (1961) 208-211.

[48] M.F. Reichmann, S.A. Rice, C.A. Thomas, P. Doty, J. Am. Chem. Soc. 76 (1954) 30473053.

[49] Rigaku/MSC. CrystalClear. Rigaku/MSC Inc., The Woodlands, Texas, USA (2005). 
[50] G.M. Sheldrick, Acta Cryst. A64 (2008) 112-122.

[51] C. Kontogiorgis, D. Hadjipavlou-Litina, J. Enz. Inhib. Med. Chem. 18 (2003) 63-69.

[52] T. Nash, Biochem. J. 55(1953) 416-421.

[53] J.R. Lakowicz, Principles of Fluorescence Spectroscopy, third ed., Plenum Press, New York (2006).

[54] L. Stella, A.L. Capodilupo, M. Bietti, Chem. Commun. (2008) 4744-4746.

[55] Y. Wang, H. Zhang, G. Zhang, W. Tao, S. Tang, J. Luminescence 126 (2007) 211-218.

[56] A. Wolfe, G. Shimer, T. Meehan, Biochemistry 26 (1987) 6392-6396.

[57] G. Zhao, H. Lin, S. Zhu, H. Sun, Y. Chen, J. Inorg. Biochem. 70 (1998) 219-226.

[58] D.P. Heller, C.L. Greenstock, Biophys. Chem. 50 (1994) 305-312.

[59] X. Meng, H. Zhang, M. Mezei, M. Cui, Current Computer-Aided Drug Des. 7 (2011) 146157.

[60] R.A. Friesner, R.B. Murphy, M.P. Repasky, L.L. Frye, J.R. Greenwood, T.A. Halgren, P.C. Sanschagrin, D.T. Mainz, J. Med. Chem. 49 (2006) 6177-6196.

[61] Schrödinger Release 2016-1: Maestro, version 10.5, Schrödinger, LLC, New York, NY, (2016).

[62] T. Halgren, Chem. Biol. Drug Des. 69 (2007) 146-148.

[63] T. Halgren, J. Chem. Inf. Model. 49 (2009) 377-389.

[64] K. Nakamoto, Infrared and Raman spectra of inorganic and coordination compounds, Part B: Applications in Coordination, Organometallic, and Bioinorganic Chemistry, sixth ed., Wiley, New Jersey (2009).

[65] A. Szorcsik, L. Nagy, J. Sletten, G. Szalontai, E. Kamu, T. Fiore, L. Pellerito, E. Kalman, J. Organomet. Chem. 689 (2004) 1145-1154.

[66] R. Mitra, M.W. Peters, M.J. Scott, Dalton Trans. (2007) 3924-3935.

[67] D.K. Garner, S.B. Fitch, L.H. McAlexander, L.M. Bezold, A.M. Arif, L.M. Berreau, J. Am. Chem. Soc. 124 (2002) 9970-9971.

[68] M. Yin, J. Sun, J. Coord. Chem. 58 (2005) 335-342. 
[69] K.A. Kounavi, C. Papatriantafyllopoulou, A.J. Tasiopoulos, S.P. Perlepes, V. Nastopoulos, Polyhedron 28 (2009) 3349-3355.

[70] X. Liu, L. Wang, X. Zhu, B. Li, Y. Zhang, Cryst. Growth Des. 9 (2009) 3997-4005.

[71] M.G. Amiri, G. Mahmoudi, A. Morsali, A.D. Hunter, M. Zeller, CrystEngComm. 9 (2007) 686-697.

[72] N. Palanisami, R. Murugavel, Inorg. Chim. Acta 365 (2011) 430-438.

[73] N. Phukan, J.B. Baruah, J. Mol. Struct. 1076 (2014) 614-619.

[74] S. Zheng, X. Wen, Z. Liu, T. Xie, J. Tan, J. Fan, S. Hou W. Zhang, Z. Anorg. Allg. Chem. 640 (2014) 2057-2061.

[75] S. Jin, D. Wang, Inorg. Chim. Acta 415 (2014) 31-43.

[76] H. Icbudak, H. Olmez, O.Z. Yesilel, F. Arslan, P. Naumov, G. Jovanovski, A.R. Ibrahim, A. Usman, H. Fun, S. Chantrapromma, S.W. Ng, J. Mol. Struct. 657 (2003) 255-270.

[77] M. Puchonova, K. Matelkova, J. Moncol, V. Jorik, M. Koman, M. Mazur, F. Jozefikova, D. Valigura, Polyhedron 98 (2015) 71-74.

[78] G. Smith, D.P. Arnold, C.H.L. Kennard, T.C.W. Mak, Polyhedron 10 (1991) 509-516.

[79] R.A. Coxall, S.G. Harris, D.K. Henderson, S. Parsons, P.A. Tasker, R.E.P. Winpenny, J. Chem. Soc., Dalton Trans. (2000) 2349-2356.

[80] R. Cini, G. Giorgi, A. Cinquantini, C. Rossi, M. Sabat, Inorg. Chem. 29 (1990) 5197-5200.

[81] R.N. Young, Eur. J. Med. Chem. 34 (1999) 671-685.

[82] P.C. Christidis, Z.D. Georgousis, D. Hadjipavlou-Litina, C.A. Bolos, J. Mol. Struct. 872 (2008) 73-80.

[83] O.A. El-Gammal, G.M. Abu El-Reash, S.E. Ghazy, A.H. Radwan, J. Mol. Struct. 1020 (2012) 6-15.

[84] K.C. Skyrianou, F. Perdih, A.N. Papadopoulos, I. Turel, D.P. Kessissoglou, G. Psomas, J. Inorg. Biochem. 105 (2011) 1273-1285.

[85] Z. Liu, B. Wang, Z. Yang, Y. Li, D. Qin, T. Li, Eur. J. Med. Chem. 44 (2009) 4477-4484.

[86] E. Pontiki, D. Hadjipavlou-Litina, Bioorg. Med. Chem. 15 (2007) 5819-5827. 
[87] C. Tan, J. Liu, H. Li, W. Zheng, S. Shi, L. Chen, L. Ji, J. Inorg. Biochem. 102 (2008) 347358.

[88] V. Rajendiran, R. Karthik, M. Palaniandavar, H. Stoeckli-Evans, V.S. Periasamy, M.A. Akbarsha, B.S. Srinag, H. Krishnamurthy, Inorg. Chem. 46 (2007) 8208-8221.

[89] O.H. Laitinen, V.P. Hytonen, H.R. Nordlund, M.S. Kulomaa, Cell. Mol. Life Sci. 63 (2006) 2992-3017.

[90] B.M. Zeglis, V.C. Pierre, J.K. Barton, Chem. Commun. (2007) 4565-4579.

[91] Q. Zhang, J. Liu, H. Chao, G. Xue, L. Ji, J. Inorg. Biochem. 83 (2001) 49-55.

[92] A.M. Pyle, J.P. Rehmann, R. Meshoyrer, C.V. Kumar, N.J. Turro, J.K. Barton, J. Am. Chem. Soc. 111 (1989) 3053-3063.

[93] G. Pratviel, J. Bernadou, B. Meunier, Adv. Inorg. Chem. 45 (1998) 251-262.

[94] A. Dimitrakopoulou, C. Dendrinou-Samara, A.A. Pantazaki, M. Alexiou, E. Nordlander, D.P. Kessissoglou, J. Inorg. Biochem. 102 (2008) 618-628.

[95] J. L. Garcia-Gimenez, M. Gonzalez-Alvarez, M. Liu-Gonzalez, B.Macias, J. Borras, G. Alzuet, J. Inorg. Biochem. 103 (2009) 923-934.

[96] W.D. Wilson, L. Ratmeyer, M. Zhao, L. Strekowski, D. Boykin, Biochemistry 32 (1993) 4098-4104.

[97] J. Ghuman, P.A. Zunszain, I. Petitpas, A.A. Bhattacharya, M. Otagiri, S. Curry, J. Mol. Biol., 353 (2005) 38-52.

[98] A. Sulkowska, J. Mol. Struct. 614 (2002) 227-232.

[99] F. Yang, Y. Zhang, H. Liang, Int. J. Mol. Sci. 15 (2014) 3580-3595.

[100] H. Isogai, N. Hirayama, ISRN Pharmaceutics (2013) Article ID 818364.

[101] A. Bujacz, K. Zielinski, B. Sekula, Proteins 82 (2014) 2199-2208.

[102] S. Bartosz, A. Bujacz, J. Med. Chem. 59 (2016) 82-89. 